\title{
The colonization and divergence patterns of Brandt's vole (Lasiopodomys brandtii) populations reveal evidence of genetic surfing
}

\author{
Ke Li ${ }^{1}$, Michael H. Kohn², Songmei Zhang ${ }^{1}$, Xinrong Wann ${ }^{3}$, Dazhao Shi ${ }^{1}$ and Deng Wang ${ }^{1 *}$ (1)
}

\begin{abstract}
Background: The colonial habit of Brandt's vole (Lasiopodomys brandtii) differs from that of most other species of the genus Microtus. The demographic history of this species and the patterns shaping its current genetic structure remain unknown. Here, we explored patterns of genetic differentiation and infered the demographic history of Brandt's vole populations through analyses of nuclear microsatellite and D-loop sequences.

Results: Phylogenetic analyses divided the sampled populations into three main clusters, which represent the southeastern, northeastern and western parts of the total range in Mongolia and China. Molecular data revealed an ancestral area located in the southeast of the extant range, in the Xilinguole District, Inner Mongolia, China, from where Brandt's vole populations began expanding. A gene flow analysis suggested that the most likely colonization route was from the ancestral area and was followed by subsequent northeastward and westward range expansions. We identified decreases in genetic diversity with increasing distance from the founder population within the newly occupied regions (northeastern and western regions), clinal patterns in the allele frequencies, alleles that were rare in the original area that have become common in the newly occupied regions, and higher genetic differentiation in the expanded range compared with the original one.

Conclusion: Our results indicate that L. brandtii most likely originated from the southeastern part of its current geographic range, and subsequently colonized into the northeastern and western parts by expansion. The genetic patterns among the derived populations and with respect to the original population are consistent with that expected under genetic surfing models, which indicated that genetic drift, rather than gene flow, is the predominant factor underlying the genetic structure of expanding Brandt's vole populations.
\end{abstract}

Keywords: Lasiopodomys brandtii, Ancestral area, Migration, Range expansion, Genetic surfing

\section{Background}

The evolutionary history of most species generally is characterized by an interplay among environmental changes, episodes of range expansion and migration, population admixtures, and local extinctions $[1,2]$. These and other factors that play roles in the past leave detectable signatures in the genetic structures of modern populations [3]. For a number of Arvicolinae rodents in

\footnotetext{
* Correspondence: wangdeng@cau.edu.cn

${ }^{1}$ College of Plant Protection, China Agricultural University, 2 Yuanmingyuan

West Road, Haidian District, Beijing 100193, China

Full list of author information is available at the end of the article
}

the Northern Hemisphere such population genetic and phylogeographic studies have been reported [3-8].

Brandt's vole (Lasiopodomys brandtii) (Radde, 1861) is a steppe-dwelling rodent species that is currently distributed from the central parts of Inner Mongolia, through the central and eastern of Republic of Mongolia, and to the southern borders of Mongolia in Trans-Baikalia, Russia $[9,10]$. Brandt's vole forms its own lineage among arvicolids rodents [10]. Over the past decades, the evolutionary origins of Brandt's vole have been studied based on paleontological, cytological and nuclear DNA data [10-15]. However, prior to this study, no direct 
molecular evidence ragarding the geographical origins of the ancestral populations or their colonization and differentiation patterns has been reported.

Brandt's vole is well adapted to the colonization of patchy, ephemeral habitats $[16,17]$, where the populations exhibit seasonal and multi-annual fluctuations in abundance [17-19]. The species distributed discontinuously across the Mongolian plateau [20]. However, the habitats are rather homogeneous [20] with respect to plant community attributes, particularly species composition, vegetation height and degree of plant cover [21]. Brandt's vole prefers degraded grasslands [22], which are often interspersed with less favorable habitats characterized by livestock grazing $[16,21,23]$. The populations of Brandt's vole show declines when the grass is shorter than approximately $5 \mathrm{~cm}$ and sparse (less than $40 \%$ cover), and do not persist well in habitats with dense coverage (more than $80 \%$ ) by tall grasses (more than 17 to $20 \mathrm{~cm}$ ) [17, 21, 24]. The environmental attributes affecting Brandt's vole populations generally are related to climate and human activities [25, 26].

Climatic changes that alter the availability of suitable habitat have can trigger range shifts and local extinctions of populations for most organisms [27]. Such effects have also been observed on the Mongolian plateau, where Brandt's vole occurs. There cold and dry climate during the Pleistocenens led to increased coverage by tundra steppe and then dry steppe habitats $[28,29]$. The forest-steppe boundary of the plateau was situated further south during the early-mid Holocene stage (10-5 kyr BP), which caused by the enhanced aridity occurred during the period [25]. Currently, it is believed that climate change and overgrazing are driving major factors that result in the degradation and desertification of Mongolian plateau pastureland [30,31]. The shifts in the distribution of Brandt's vole populations are expected to result from species migration and/or adaptation to the environment. Biotope evolutionary changes, such as soil development [26], hydrological changes [32], desertification [33], and landscape evolution [34] in the Mongolia plateau inhabited by extant and extinct Brandt's voles should impact the population dynamics. Such changes should also interfere with the genetic composition of the population. Through fine-scale geographic sampling in well-defined ecological and historical contexts, it is possible to detect cases of spatially varying selection that involve subtle shifts in the allele frequency among locally adapted populations [35-38].

Here we used microsatellite data and mtDNA D-loop sequences to describe the phylogeography and genetic diversity of Brandt's vole populations over space and time, and to infer the population demography history. We reconstructed the likely geographic origin of the species and past colonization routes. Genetic surfing is a phenomenon associated with species displaying rapid population growth, a patchy distribution, and rapid population growth [27, 39]. As part of the genetic surfing phenomenon, the frequency of alleles arising on the leading edges of the wave of range expansion can increase to high levels due to genetic drift; in other words, once rare alleles might become predominant in populations colonizing the new territory [27]. The phenomenon has attained some attention because under such a scenario, the relative position of an individual and the alleles it carries more strongly affect the fate of alleles than selection or standard genetic drift occurring in a Fisher-Wright population or stable populations of small effective size [39]. Thus, during our study we paid particular attention to the possibility of empirically demonstrating the phenomenon in Brandt's vole.

\section{Methods \\ Sampling}

A total of 851 Brandt's voles were captured using livetraps from 23 sites in Inner Mongolia (China) and Mongolia (Fig. 1b). Twelve populations from Mongolia were collected in July 2010, whereas the populations from Inner Mongolia were trapped in July 2008 and 2009. A summary of the populations is provided in Additional file 1: Table S1. All samples were captured by regular live trapping for two successive days at geographic locations spanning $>5$ hectars (ha) in size. Traps were baited with peanuts and set at burrow entrances in the morning until no new voles entranced. Each captured animal was weighed, sexed and was given unique identification numbers by toe-clipping according to Wood \& Slade [40]. Adults were selected for the analyses to avoid obvious sampling parent-offspring pairs. All toe clippings were immediately placed in $70 \%$ ethanol and stored at $-20{ }^{\circ} \mathrm{C}$ until used for DNA extraction. A total of 26-63 individuals were collected from each site with the exception of Hangwula and Modamuji, where trapping success was low.

\section{DNA extraction, microsatellite genotyping and D-loop sequencing}

Genomic DNA was extracted using the proteinase-K digestion and phenol-chloroform extraction method as described by Sambrook et al. [41]. All individuals were genotyped at 12 microsatellite loci [42, 43]. Primer sets are provided in Additional file 1: Table S2. DNA amplification was performed in a thermocycler (Model 9700, Applied Biosystems, USA). The $15-\mu \mathrm{L}$ reaction mixtures contained $\sim 50 \mathrm{ng}$ of DNA, $1 \times$ PCR buffer, $0.2 \mu \mathrm{M}$ of each primer, $1.0-2.5 \mathrm{mM} \mathrm{MgCl}_{2}, 0.2 \mathrm{mM}$ of each nucleotide, $1 \mathrm{U}$ of Taq polymerase (TaKaRa Bio Company, Dalian, China), and $\mathrm{ddH}_{2} \mathrm{O}$. The amplification program consisted of an initial denaturation for $10 \mathrm{~min}$ at $95{ }^{\circ} \mathrm{C}$ 


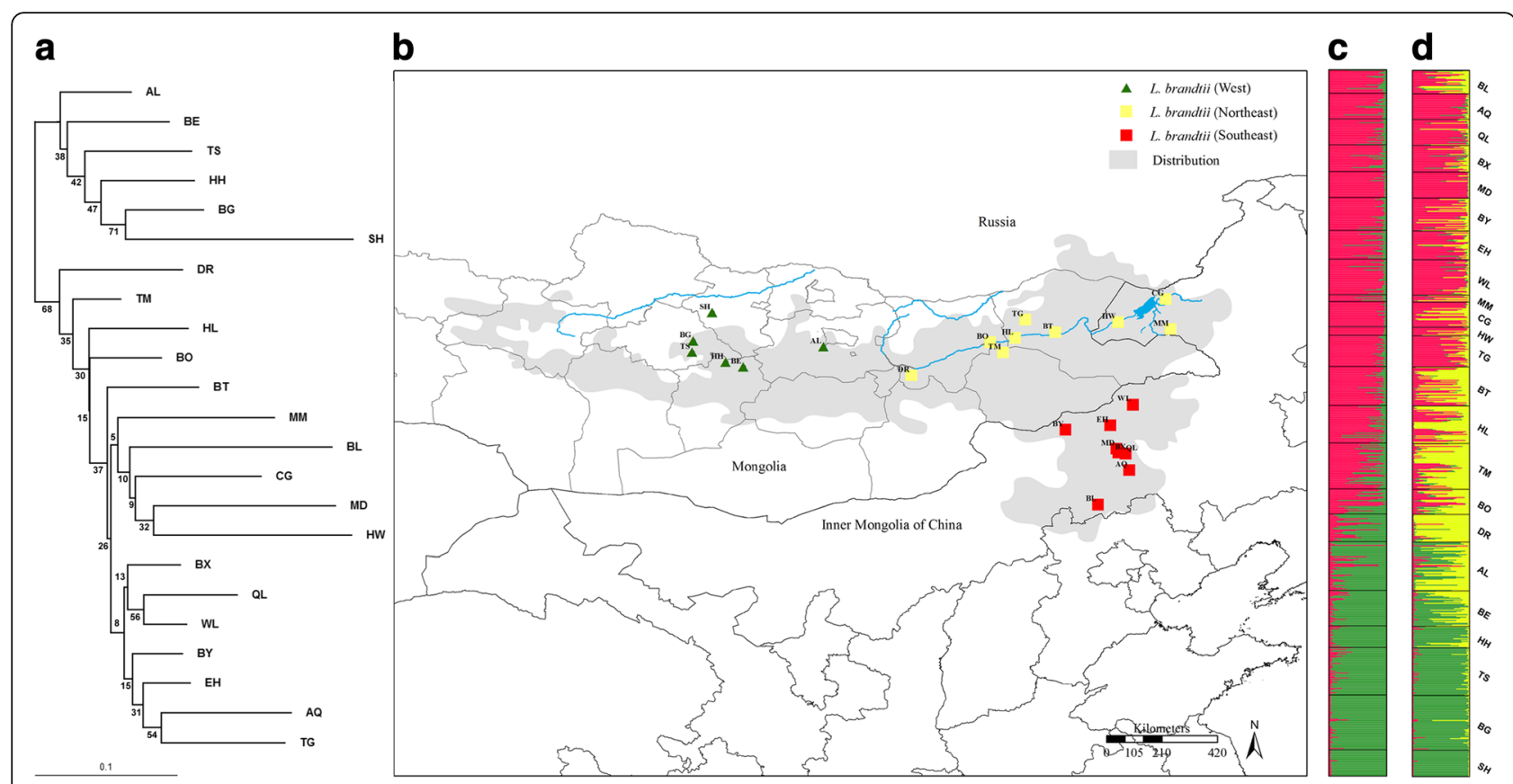

Fig. 1 Population structure of Brandt's vole $(N=814)$ from 23 sites based on nuclear microsatellite data. a Neighbor-joining ( $N J)$ tree based on pairwise genetic distances $\left(D_{a}\right)$ between sampling sites depicted in $\mathbf{b}$ ); $\mathbf{c}$ Bayesian structure plot for $K=2$. $\mathbf{d}$ Analysis with $\mathrm{K}=3$. Coloring scheme of symbols reflects STRUCTURE results. Detailed sampling information is provided in Additional file 1: Table S1

followed by 35 cycles of $40 \mathrm{~s}$ at $94{ }^{\circ} \mathrm{C}$ for denaturation, $40 \mathrm{~s}$ for annealing, and $40 \mathrm{~s}$ at $72{ }^{\circ} \mathrm{C}$ for extension and a final extension for $10 \mathrm{~min}$ at $72{ }^{\circ} \mathrm{C}$. The PCR products were analyzed using an ABI PRISM3730 DNA Sequencer (Applied Biosystems). Genotypes were scored using GeneMarker 1.7 (Applied Biosystems). Two observers identified genotypes independently. If the genotypes of the same vole and locus differed, the genotyping process was repeated until a consensus was reached. Allelic dropout and the presence of null alleles were screened using Micro-Checker version 2.2 [44]. Ninety-eight randomly selected samples ( $12 \%$ of all samples) were genotyped again, and the results were analyzed using the Gimlet program [45] to estimate the rates of different types of errors.

A 734-bp fragment of the D-loop sequence was amplified by PCR from 746 individuals using the primer pairs (5'-ACCATCAACACCCAAAGC-3' and 3'-GTACTTGATACCCTCTCC-5') designed with Primer 5 [46] based on the sequence of Lasiopodomys mandarinus with GenBank accession number NC_025283.1. The PCR was performed in $25-\mu \mathrm{L}$ reaction mixtures containing $25 \mathrm{ng}$ of genomic DNA, $1 \times$ PCR buffer, $0.2 \mu \mathrm{M}$ of each primer, $1.5 \mathrm{mM} \mathrm{MgCl}_{2}, 0.2 \mathrm{mM}$ of each nucleotide, $1 \mathrm{U}$ of Taq polymerase (TaKaRa Bio Company, Dalian, China), and $\mathrm{dd}_{2} \mathrm{O}$. The reaction was optimized and programmed over 35 cycles using a GeneAmp PCR system 9700 thermocycler (Applied Biosystems) with the following temperature profile: $5 \mathrm{~min}$ at $94{ }^{\circ} \mathrm{C}$ for denaturation; followed by 10 cycles of $30 \mathrm{~s}$ at $94{ }^{\circ} \mathrm{C}$ for denaturation, $30 \mathrm{~s}$ at $60{ }^{\circ} \mathrm{C}$ for annealing, and $70 \mathrm{~s}$ at $72{ }^{\circ} \mathrm{C}$ for extension; 15 cycles of $30 \mathrm{~s}$ at $94{ }^{\circ} \mathrm{C}, 30 \mathrm{~s}$ at $55^{\circ} \mathrm{C}, 70 \mathrm{~s}$ at $72{ }^{\circ} \mathrm{C}$; and 10 cycles of $94{ }^{\circ} \mathrm{C}$ for $30 \mathrm{~s}, 50{ }^{\circ} \mathrm{C}$ for $30 \mathrm{~s}, 72{ }^{\circ} \mathrm{C}$ for $70 \mathrm{~s}$; and a final extension step for 7 min at $72{ }^{\circ} \mathrm{C}$. All PCR products were sequenced in a single direction using an automated ABI 3730 DNA sequencer (Sangon Biotech Ltd). The sequences were aligned to the corresponding D-loop regions of $L$. mandarinus using the programs Lasergene 7.2 [47] and CLUSTALX [48] and were checked and edited manually using Lasergene 7.2. The D-loop haplotype sequences from Brandt's voles were deposited in GenBank (GenBank nos: KY354521KY354550).

\section{Genetic diversity and phylogenetic analyses}

Hardy-Weinberg equilibrium (HWE) tests based on the excess of heterozygosity were performed for all loci using GENEPOP v4.5 [49]. Each test was run for 1000 dememorization steps, followed by 100 batches of 1000 steps each. $P$-values were adjusted using the Bonferroni correction [50]. We used GENALEX 6.5 [51] to estimate the number of alleles $\left(N_{a}\right)$, allele frequencies, private and rare alleles (allelic frequencies under 0.05), and observed $\left(H_{o}\right)$ and expected heterozygosity $\left(H_{e}\right)$ for each sampling site and for cluster inferred from phylogenetic analyses (see below). Pairwise population differences were also explored with the use of Wright's $F_{\mathrm{ST}}$ values. The allelic richness $\left(A_{r}\right)$ was calculated for each site population 
based on a minimum sample size of 14 using the rarefaction procedure implemented in HP-Rare [52].

We used Poptree2 [53] to construct a neighbor-joining (N) tree for all Brandt's vole populations based on the pairwise genetic distances $\left(D_{a}\right)$ generated from microsatellite genotypes, and we used a Bayesian MCMC assignment method implemented in STRUCTURE 2.3 [54] to assign individuals to inferred clusters based on multilocus genotypes. The admixture ancestry and the correlated allele frequencies model were implemented in STRUCTURE, with K (the number of clusters) set to a value between 1 and 23, and 20 independent iterations consisting of 100,000 burn-in steps and an iteration length of 100,000 were performed for each value of K. The results subsequently were processed by STRUCTURE HARVESTER (http://taylor0.biology.ucla.edu/ structureHarvester/) [55] to delineate the most likely level of population subdivision (the appropriate $\mathrm{K}$ ), which was identified using the maximal values of a statistic $\Delta \mathrm{K}$ based on the rate of change in the log probability of the data between successive K-values [56]. The output from STRUCTURE was visualized using the DISTRUCT program (http://www.stanford.edu/group/ rosenberglab/distructDownload.html). We also performed AMOVA analysis with ARLEQUIN [57] to test for the genetic differentiation within and among clusers.

Polymorphism indices of the D-loop sequences including the number of haplotypes $(\mathrm{N})$, nucleotide diversity $(\pi)$ and haplotype diversity $(H d)$, were calculated for each sampling site, each cluster and diverged groups of haplotypes (haplogroups obtained from phylogenetic analysis, c.f. Figs. 2 and 3a) using DNASP 5.0 [58].

We estimated the phylogenetic relationships among haplotypes using the Bayesian method implemented in BEAST v2.1.3 [59]. We consider three rodent species to be the most adequate outgroups of L. brandtii: L. mandarinus (GenBank nos. NC_025283.1, JX014233.1 and KF819832.1) always form the sister group with L. brand$t i i$, and it can be rather closely related but clearly outside of $L$. brandtii in the phylogenetic relationship [3, 60]. Microtus oeconomus (GenBank nos. HM135921, AJ616853 and HM135928) and Microtus arvalis (GenBank no. KP013595) have more distant in the molecular phylogeny of Microtus species [3, 60, 61]. Paleontological and molecular phylogenetic analysis suggested that Lasiopodomys might be part of the sister clade to Microtus [10, 62]. We used the HKY substitution model as selected by Akaike's Information Criterion [63] in MODELTEST [64] and a strict clock model generated by Bayes factors [65]. The Yule model was selected as tree prior model; MCMC chains were run for 50 million iterations with parameters sampled every 1000 iterations; Trees were combined in TreeAnnotator v2.1.3 [66] with 50\% burn-in values. Tracer v1.5.0 [67] was used to check for the convergence of Markov chains and to ensure sufficient sampling. Expected sample sizes (ESSs) for all parameters were greater than 100 . The maximum clade credibility tree was visualized using Figtree v1.4.2 [68]. We constructed a Median-Joining (MJ) network for D-loop haplotypes using Network5.0 [69]. We performed AMOVA to test for the differentiation within and among cluster and haplogroup using ARLEQUIN [57]. The geographic distributions of the haplotypes were visualized on a map using ArcGIS v10.1 [70].

Divergence times separating haplogroups were estimated using the Bayesian method implemented in BEAST v2.1.3. To conduct the dating runs, we manipulated a Calibrate Yule tree prior as the tree model and a strict clock model. The divergence time between L.mandarinus and L.brandtii (0.5-0.95 Ma) [3] was assumed to be the calibration time. MCMC chains were run for 50 million iterations with parameters sampled every 5000 generations and 10\% burn-in values. Tracer 1.5 was used to assess ESSs for all paremeters and to verify that the posterior distribution of the divergence calibration matches the prior distribution. Trees were combined in TreeAnnotator v2.1.3 and node ages were visualized using Figtree v1.4.2.

\section{Inferring ancestral areas and modeling colonization routes}

We used three clusters (as obtained from D-loop) for ancestral area reconstruction. They were partitioned in the western (W), southeastern (SE) and northeastern (NE) based on the D-loop phylogenetic analysis (Fig. 3c; Table 2). We performed a Statistical-DispersalVicariance-Analysis (S-DIVA) in a Bayesian framework implemented in RASP v3.2 [71, 72], and DispersalExtinction-Cladogenesis process (DEC) in a likelihood framework using Lagrange $[73,74]$ to reconstruct the likely geographic history of Brandt's vole. We ran SDIVA on 10,000 trees from MCMC output to account for phylogeny uncertainties. We opted for not constraining the dispersal probabilities to avoid overparameterization for the DEC analysis. The number of maximum areas was set as 2 for both two analyses. The input tree for the analyses was generated from BEAST (Fig. 2). For Lagrange, a Python script was created using the online Lagrange configurator.

To explore the dispersal process and historical gene flows, we applied MIGRATE-N v.3.6.1 $[75,76]$ to the microsatellite data for both two distinct clusters (eastern and western distribution) (Additional file 2: Fig. S1) and three clusters (southeastern, northeastern and western distribution) supported by the phylogenetic results (Fig. 1; Additional file 2: Fig. S1; Table 2). MIGRATE-N, implements coalescent-based MCMC simulations, was applied to estimate $\Theta, M$ and the marginal likelihood of the specified gene flow models [76]. The population size 


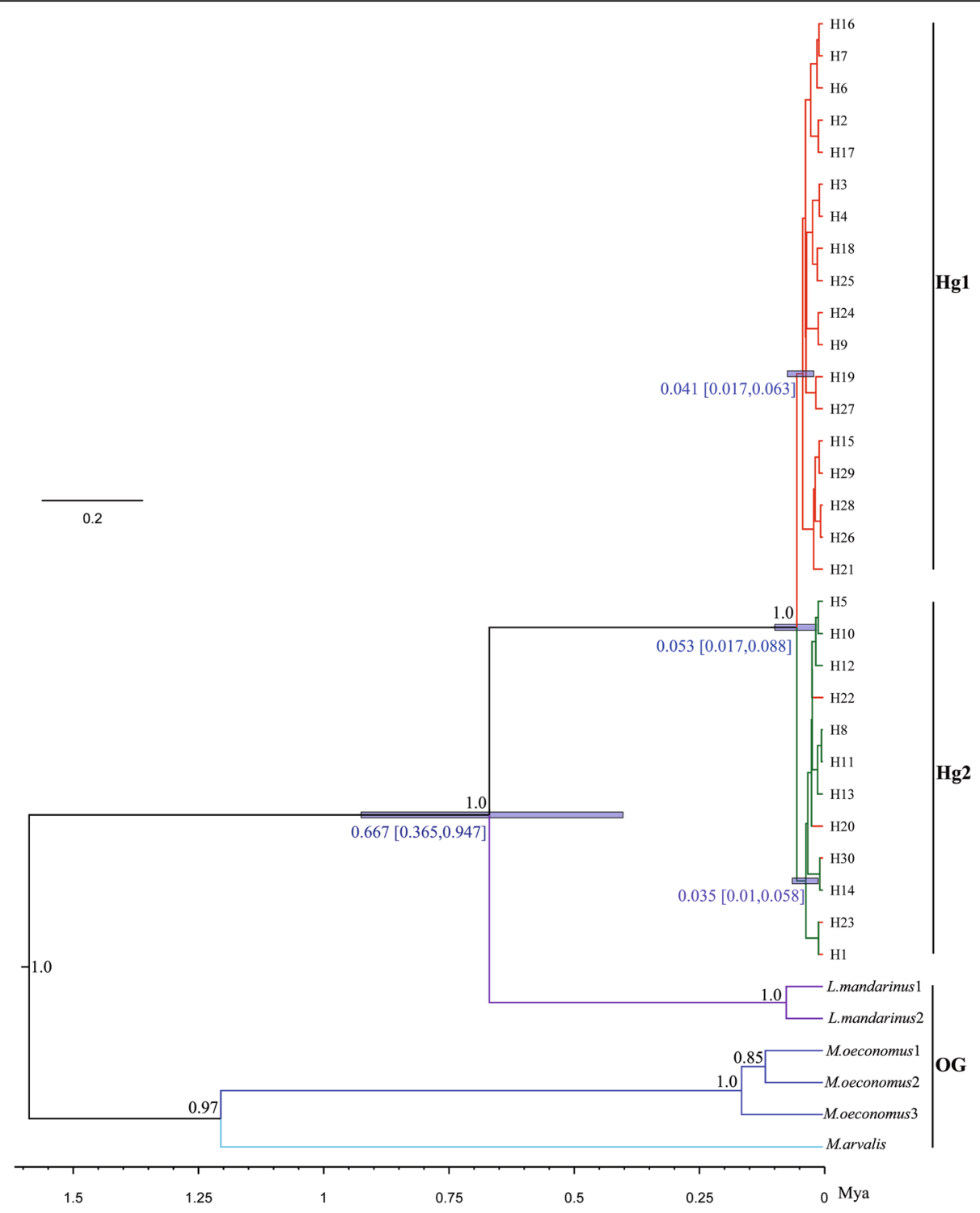

Fig. 2 Phylogenetic analysis of Brandt's vole. Maximum clade credibility tree reconstructed using D-loop haplotypes. The posterior probability ( $\geq 0.85$ ) clades are presented at nodes (black numbers). Blue bars correspond to the 95\% HPD for TMRCA (blue numbers). L. mandarinus, M. oeconomus and M. arvalis are used as outgroups. Branch color denotes the geographic distribution of haplotypes (coloring scheme as in Fig. 3c)

$\Theta$ is defined as $4 N_{e} \mu$, where $N_{e}$ is the effective population size and $\mu$ is the mutation rate of loci per generation, and the migration rate $M$ is equivalent to $m / \mu$, where $m$ is the immigration rate per generation [75]. Preliminary runs were performed using the full migration model to determine the optimal parameters. We performed runs through Bayesian inference using the following parameters: slice sampling, an exponential prior distribution for $\Theta$ (min: 0 , mean: 35, max: 70), an exponential prior distribution for migration (min: 0, mean: 750, max: 1500), static heating with temperatures of $1.00,1.50,3.00$ and $10^{6}$; potential occurrence of swapping among chains at every step; and $10^{4}$ burn-in steps followed $5 \times 10^{7}$ parameter samplings recorded at intervals of $10^{3}$. We randomly selected 20 individuals per population for our MIGRATE-N analyses due to computational demands and the evidence that more than 20 individuals do not increase the accuracy of parameter estimations [77]. All final reported runs met the convergence criteria for ESSs greater than $10^{4}$ and showed good agreement between the mean and median estimates for all parameters. The posterior distribution plot of each parameter was also used to visually test for convergence. The marginal likelihood and probability of each model was approximated using a Bezier-corrected thermodynamic integration $[76,78]$. 


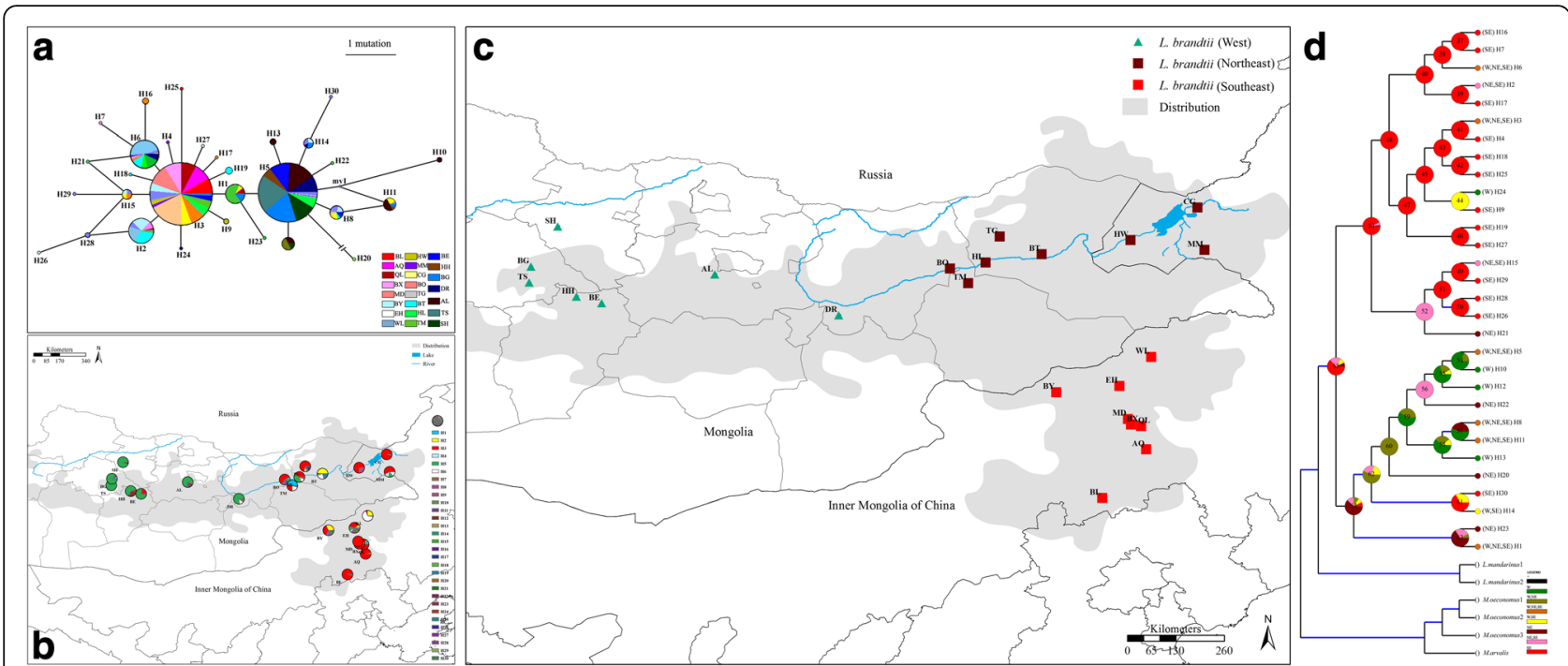

Fig. 3 Population structure and history of Brandt's vole $(N=746)$ from 23 sites inferred from D-loop data. a Median-joining network of 30 haplotypes. Circle sizes indicate haplotype frequencies. The colored segments indicate the sample size of voles available for each geographic location specified by the color key (black square, mv1, represents missing or unsampled haplotypes. b Geographic distributions of haplotypes found in c. d Ancestral area reconstruction, where W, NE and SE represent western, northeastern and southeastern distributions, respectively (color coding as in c). Pie charts on each node show the posterior probability (PP) of each ancestral haplotype occurring at an inferred ancestral geographic location as inferred with the S-DIVA method. Node codes (37-65) are shown on pie charts. (c.f. Additional file 3: Table S9 for numerical results obtained using S-DIVA and DEC). Probabilities $<5 \%$ were lumped together as "**. Blue branches indicate PP $>0.69$

\section{Testing for range expansion}

We used DNASP 5.0 [58] to conduct neutrality tests [79-81] on D-loop sequence data. Past population size changes were inferred by computing a raggedness index (r) obtained from a site mismatch analysis [82, 83] and by comparing the observed distribution to the distribution under the null model of constant population size.

Effective population size fluctuations over time were inferred using a Bayesian Skyline plot method (BSP) implemented in the program package BEAST v2.1.3. The GTR model was run for the entire population and for each D-loop haplogroup separately. Substitution rate for the D-loop sequences estimated for Meriones was similar to Microtus [84]. We used the substitution rate of $1.27 \times 10^{-7}$ substitutions per site per year in D-loop estimated for Meriones meridianus (95\% confidence interval $=1.2 \times 10^{-7}$ to $1.33 \times 10^{-7} /$ site/year) [84] to scale the time axis of BSPs. The chains were run for 200 (entire samples) and 40 (haplogroups) million iterations respectively, of which the first $10 \%$ were discarded. Model parameters were sampled every 1000 iterations. The posterior samples were combined using LogCombiner [59]. Skyline plots were generated using Tracer v1.5.0. ESSs for all parameters were greater than 100 .

The isolation by distance was tested for all site populations in Brandt's vole through a regression of pairwise $F_{\mathrm{ST}} /\left(1-F_{\mathrm{ST}}\right)$ values on the $\ln \mathrm{GD}$ (geographic distance among populations) [85] using SPSS v.20 [86]. The pairwise $F_{\mathrm{ST}}$ valuas were calculated based on the microsatellite data using ARLEQUIN 3.5 [57]. We also performed IBD tests for different clusters as described above (Fig. 1b).

In a pairwise manner for each of the three clusters, we iteratively calculated the average $F_{\mathrm{ST}}$ between samples obtained from one site of each cluster and all samples from all sites that are part of another cluster. According to Graciá et al. [87], those samples (and the sampling site they represent) that have the lowest average $F_{\mathrm{ST}}$ and the highest allelic richness $\left(A_{r}\right)$ was regarded as those representing the likely starting point from which the species began colonizing, and samples (and the sampling site they represent) with the lowest average $F_{\mathrm{ST}}$ value was considered as those representing probable newly established derived populations occupying the new territory, or arrival sites. Range expansion is expected to cause a decrease in intrademe heterozygosity with an increase in $F_{\mathrm{ST}}$ as a function of the distance from the inferred starting point of colonization [88-91]. We regressed the $H_{e}, A_{r}$ and allele frequencies of each sampling site against the distance to the inferred starting or arrival sites within each cluster as inferred as described above from microsatellite data (Fig. 1b). Due to departures from IBD for the southeastern, northeastern and western clusters (Figs. $1 \mathrm{~b}$ and 6), we conducted these analyses using the corresponding $F_{\mathrm{ST}}$ values instead of the geographic distance, as in such a case $F_{\mathrm{ST}}$ might more accurately reflect the dispersal distance between sites. Statistical analyses were performed using SPSS v.20. 


\section{Results}

\section{Genetic diversity of Brandt's vole populations}

No significant linkage disequilibrium was detected amongst any of the 12 pairwise microsatellite loci combinations. The genotyping results are listed in Additional file 1: Table S1, and characteristics of the microsatellite markers are summarized in Additional file 1: Table S2. The MICROCHECKER results suggested no notable scoring errors (the error rate of most loci was less than 0.05) due to stuttering or allele dropout. The number of alleles for each population across loci ranged from 3.83 (HW) to 8.17 (BY), with an average of 6.33. The mean observed heterozygosity $\left(H_{o}\right)$ and expected heterozygosity $\left(H_{e}\right)$ were 0.68 ( 0.54 for BL to 0.75 for $\mathrm{AL})$ and 0.66 (0.55 for $\mathrm{SH}$ to 0.75 for $\mathrm{AL}$ ), respectively. The mean allelic richness $\left(A_{r}\right)$ was 4.66 (3.39 for $\mathrm{SH}$ to 5.61 for $\mathrm{AL}$ ) (Additional file 1: Table S3). Significant deviations from the HardyWeinberg expectation were found for 11 loci in some populations $(P<0.05)$ (Additional file 1: Table S4).

The analysis of D-loop sequences revealed 30 haplotypes based on 29 segregating sites (including insertions and deletions) observed in the 746 individuals sequenced. Of the 30 haplotypes, 14 were singletons, six were shared among individuals within geographical locations, and 10 were shared among different geographical locations (Additional file 1: Table S5). The global haplotype diversity $(H d)$ was 0.73 , with a range from 0 for MD and TS to 0.83 for EH (Additional file 1: Table S6).

The Bayes tree and MJ network tree of D-loop haplotypes defined two haplogroups: hap_group1 (Hg1) and hap_group2 (Hg2) (Figs. 2 and 3a). Hg1 consisted of 18 haplotypes that are mainly found in the eastern distribution, and $\mathrm{Hg} 2$ consisted of 12 haplotypes that occurred mainly in the western distribution (Fig. 3b; Table 1). The predominant haplotypes (Hg1-H3 and $\mathrm{Hg} 2-\mathrm{H} 5)$ were detected 288 and 247 times, respectively (Additional file 1: Table S5).

\section{Genetic structure of Brandt's vole populations}

The partitioning of the entire data set using the Bayesian method implemented in the STRUCTURE revealed the presence of two or three genetic clusters, with a maximum log likelihood of posterior probability $[\ln \mathrm{P}(\mathrm{X} / K)=-33,067]$ and maximum $(\Delta K=226.2)$ at
$K=2$ (Additional file 2: Fig. S1). The sample sites at AL, $\mathrm{BE}, \mathrm{HH}, \mathrm{BG}, \mathrm{SH}$, TS and DR belong to a western cluster, in western Mongolia. The other locations grouped as eastern cluster were predominantly found in Inner Mongolia, China (Fig. 1b \& c). With the exception that DR was partitioned into the eastern, the phylogenetic relationships were broadly consistent with NJ tree constructed from the microsatellite pairwise genetic distance $\left(D_{a}\right)$ matrix (Fig. 1a). At $K=3$ (Additional file 2: Fig. S1), BT, HL, TM, DR and BO emerged as a distinct cluster in the northeastern region, and the other locations were divided into two clusters that geographically corresponded to the western (including MM, CG, HW, $\mathrm{AL}, \mathrm{BE}, \mathrm{HH}$, $\mathrm{BG}, \mathrm{SH}$ and TS) and southeastern distributions (including BL, AQ, QL, BX, MD, BY, EH, WL and TG) (Fig. 1b \& d).

For all populations, a $9.02 \%$ of microsatellite variation was distributed among site populations (AMOVA, $P<0.0001$ ). For the two clusters (partitioning AL, BE, $\mathrm{HH}$, TS, BG and $\mathrm{SH}$ in the western distribution and the other populations in the eastern), 3.3\% $(P<0.0001)$ of the total variation accounted for the among clusters (Fig. 1b; Table 2$)$, whereas a smaller proportion $(2.93 \%, P<0.0001)$ of total variation emerged between clusters $\left(\mathrm{F}_{\mathrm{CT}}=0.33\right.$, $P<0.0001)$ if DR was assigned to the western cluster (Table 2). Based on the three genetic clusters identified by the analysis using STRUCTURE (Fig. 1b \& d) as well as the results obtained during AMOVA for the two clusters (Table 2), we divided the 23 populations into 3 clusters (southeastern, northeastern and western distributions) (Fig. 1b). In this scenario, a $2.6 \%(P<0.0001)$ of the total variation was assigned to the among clusters (Table 2). For the microsatellite data we considered a structure consisting of two and three clusters for modeling gene flow and verification of the genetic surfing theory in Brandt's vole.

The Bayes tree (Fig. 2) and MJ network (Fig. 3a) constructed from the D-loop data revealed a phylogeographic pattern where related haplogroups generally were distributed following our two-cluster model for D-loop sequences (Fig. 3b). Haplogroup 1(Hg1) consisted of 18 haplotypes associated primarily with the eastern region, whereas $\mathrm{Hg} 2$ associated mainly with the western region (Fig. 3b; Additional file 1: Table S5). Five haplotypes ( $\mathrm{H} 1, \mathrm{H} 20, \mathrm{H} 22, \mathrm{H} 23$ and $\mathrm{H} 30)$ in $\mathrm{Hg} 2$ were

Table 1 Polymorphism and demographic statistics inferred from D-loop data for haplogroups in Brandt's vole

\begin{tabular}{lllllllll}
\hline Haplogroup & $n$ & $N$ & $H d$ & $\pi$ & Tajima's D & Fu's & SSD & Raggedness \\
\hline Hg1 & 418 & 18 & 0.5541 & 0.0385 & $-1.7622^{* *}$ & $-18.5179^{* *}$ & $0.007^{\text {ns }}$ & $0.1134^{* *}$ \\
Hg2 & 328 & 12 & 0.3171 & 0.0318 & $-1.9326^{* *}$ & $-6.7297^{* *}$ & $0.0003^{\text {ns }}$ & $0.2459^{\text {ns }}$ \\
Overall & 746 & 30 & 0.728 & 0.0021 & $-1.5135^{*}$ & $-18.5425^{* *}$ & $0.013^{* *}$ & $0.0531^{\text {ns }}$
\end{tabular}

$n$ Sample size, $N$ number of haplotypes, $H d$ haplotype diversity, $\pi$ nucleotide diversity, Tajima's $D$ Tajima's $D$ value, Fu's Fu and Li's D value, SSD goodness-of-fit to a simulated population expansion, and Raggedness Harpending's Raggedness index estimated under demographic expansion model. (ns: $P>0.05, *$ : $P<0.05,{ }^{* *}$. $P<0.01$ ). (Hg1: H2, H3, H4, H6, H7, H9, H15, H16, H17, H18, H19, H21, H24, H25, H26, H27, H28, H29; Hg2: H1, H5, H8, H10, H11, H12, H13, H14, H20, H22, H23, H30) (Figs. 2 and $3 a$ \& b) 
Table 2 AMOVA analysis of microsatellite and D-loop data in Brandt's vole populations

\begin{tabular}{|c|c|c|c|c|}
\hline & Microsatellite & $P$ & D-loop & $P$ \\
\hline & \multicolumn{2}{|l|}{$\begin{array}{l}\text { Percentage of } \\
\text { variation }\end{array}$} & \multicolumn{2}{|l|}{$\begin{array}{l}\text { Percentage of } \\
\text { variation }\end{array}$} \\
\hline & 23 populations & & 23 populations & \\
\hline Among populations & 9.02 & $0.000^{* * *}$ & 52.46 & $0.000^{* * *}$ \\
\hline \multirow[t]{2}{*}{ Within populations } & 90.98 & & 47.54 & \\
\hline & 2 clusters & & 2 clusters & \\
\hline Among clusters & 3.3 & $0.000^{* * *}$ & 59.7 & $0.000^{* * *}$ \\
\hline $\begin{array}{l}\text { Among populations } \\
\text { within clusters }\end{array}$ & 7.33 & $0.000^{* * *}$ & 7.24 & $0.000^{* * *}$ \\
\hline \multirow[t]{2}{*}{ Within populations } & 89.38 & $0.000^{* * *}$ & 33.06 & $0.000^{* * *}$ \\
\hline & 3 clusters & & 3 clusters & \\
\hline Among clusters & 2.6 & $0.000^{* * *}$ & 50.86 & $0.000^{* * *}$ \\
\hline $\begin{array}{l}\text { Among populations } \\
\text { within clusters }\end{array}$ & 7.13 & $0.000^{* * *}$ & 8.90 & $0.000^{* * *}$ \\
\hline \multirow[t]{2}{*}{ Within populations } & 90.27 & $0.000^{* * *}$ & 40.25 & $0.000^{* * *}$ \\
\hline & $\begin{array}{l}2 \text { clusters } \\
\text { (DR in the western) }\end{array}$ & & 2 haplogroups & \\
\hline $\begin{array}{l}\text { Among clusters/ } \\
\text { groups }\end{array}$ & 2.93 & $0.000^{* * *}$ & 75.99 & $0.000^{* * *}$ \\
\hline $\begin{array}{l}\text { Among populations } \\
\text { within clusters } \\
\text { /groups }\end{array}$ & 7.46 & $0.000^{* * *}$ & - & - \\
\hline Within populations & 89.61 & $0.000^{* * *}$ & 24.01 & \\
\hline
\end{tabular}

For clusters (using microsatellite or D-loop) and haplogroup definitions see Figs. 1b, 2, 3c and Table 1, respectively. (ns: $P>0.05,{ }^{*}: P<0.05$, **: $\left.P<0.01,{ }^{* * *} P<0.001\right)$

deviated from the pattern and mainly occurred in the eastern. However, except for $\mathrm{H} 1$ that was frequent (found in 27 samples) all others are singletons. All clades of $L$. brandtii in the Bayes tree give weight to a monophyletic species. Estimates of posterior probability in the Bayes tree (Fig. 2) support the monophyly of L. brandtii, consisting of haplogroups 1 and 2 .

AMOVAs using D-loop data revealed that 52.46\% $(P<0.0001)$ of the total variation was distributed among populations for all samples; $75.99 \%(P<0.0001)$ of the total variation was distributed among the two haplogroups; and $59.7 \%(P<0.0001)$ of the total variation was distributed between the eastern and western clusters, resulting in maximization of genetic differences (Fig. 3c; Table 2). Under the three clusters scenario a $50.86 \%$ $(P<0.001)$ of the total variation was distributed among clusters (Table 2). Divergence time estimation showed that $\mathrm{Hg} 1$ and $\mathrm{Hg} 2$ split occurred at about 0.053Mya (Million years age) with a $95 \%$ highest posterior density (HPD) of $0.017-0.088$. The basal differentiation of $\mathrm{Hg} 1$ clade occurred at 0.041 Mya and 0.035 Mya for Hg2 (Fig. 2).

\section{Reconstruction of ancestral area and migration route} Based on the estimates of divergence time, Hg1(eastern) appears to have diverged earlier than Hg2 (Fig. 2). The ancestral areas inferred using S-DIVA and DEC were in broad agreement. The basal node 65 from S-DIVA displayed two possible ancestral ranges, SE (southeastern) and NE+ SE (northeastern + southeastern), and the probability of the two ancestral ranges were $63.5 \%$ and 20.9\%, respectively (Fig. 3d; Additional file 1: Table S8). DEC yielded the same two ancestral ranges with S-DIVA, and the probability of these ranges at node 65 were 0.76 and 0.12 for $\mathrm{SE}$ and $\mathrm{NE}+\mathrm{SE}$, respectively (Additional file 1: Table S8). These results provided support for the ancestors of Brandt's vole occurring in the southeastern portion of its distribution (Fig. 3c).

We applied MIGRATE-N to the microsatellite data and found that Model 1 had the highest likelihood (Fig. 4; Table 3), thus consistent with the results for the D-loop data that Brandt's vole originated from the eastern part of its current distribution (Fig. 3d). Under this scenario we evaluated nine migration models (Fig. 4). We found that Model 4 had the highest probability, implying that Brandt's vole originated and spread from the southeast first in a northeastern direction and subsequently to the western ranges (Table 3). Notably, this Model 4 is somewhat unique in that it considered features of the landscape that may affect dispersal, i.e., the Gobi desert located at the border of Mongolia and Inner Mongolia of China [10, 92]. The other models were based on Model 4 but included additional direct migrations or backflows (Fig. 4).

\section{Range expansion analysis of Brandt's vole}

We applied neutrality tests, mismatch distributions, and Bayes Skyline Plot (BSP) to the entire mtDNA data, and Hg1 and Hg2 (see above). The MJ network (Fig. 3a) already revealed a star-like pattern, with two centrally placed geographically widespread haplotypes $\mathrm{H} 3$ and $\mathrm{H} 5$ found in 19 and 13 sites throughout the eastern and western, respectively (Additional file 1: Table S5). For the entire population, Tajima's $\mathrm{D}(-1.5135, P<0.05)$ and Fu and Li's $\mathrm{F}(F=-18.5425, P<0.01)$ were both significantly negative (Additional file 1: Table S6), and the mismatch distributions were unimodal with low Harpending's $r$ (raggedness $=0.0531, P>0.05$ ) (Fig. 5a). When haplogroups were analyzed separately, the neutrality tests and mismatch distributions of $\mathrm{Hg} 1$ and $\mathrm{Hg} 2$ were consistent with rapid population size expansions (Fig. 5b \& c; Table 1). The BSP also showed the signs of population expansion for the entire population as well as for $\mathrm{Hg} 1$ and $\mathrm{Hg} 2$, with an estimated time since population expansion for entire population of $\sim 2000$ years $\mathrm{BP}$, and for $\mathrm{Hg} 1$ and $\mathrm{Hg} 2$ of $\sim 1000$ years BP and $\sim 200$ years BP, respectively (Fig. $5 \mathrm{~d}-\mathrm{f}$ ). The lower diversity within $\mathrm{Hg} 2$ compared to $\mathrm{Hg} 1$ is consistent with such a more recent expansion (Table 1 ). 


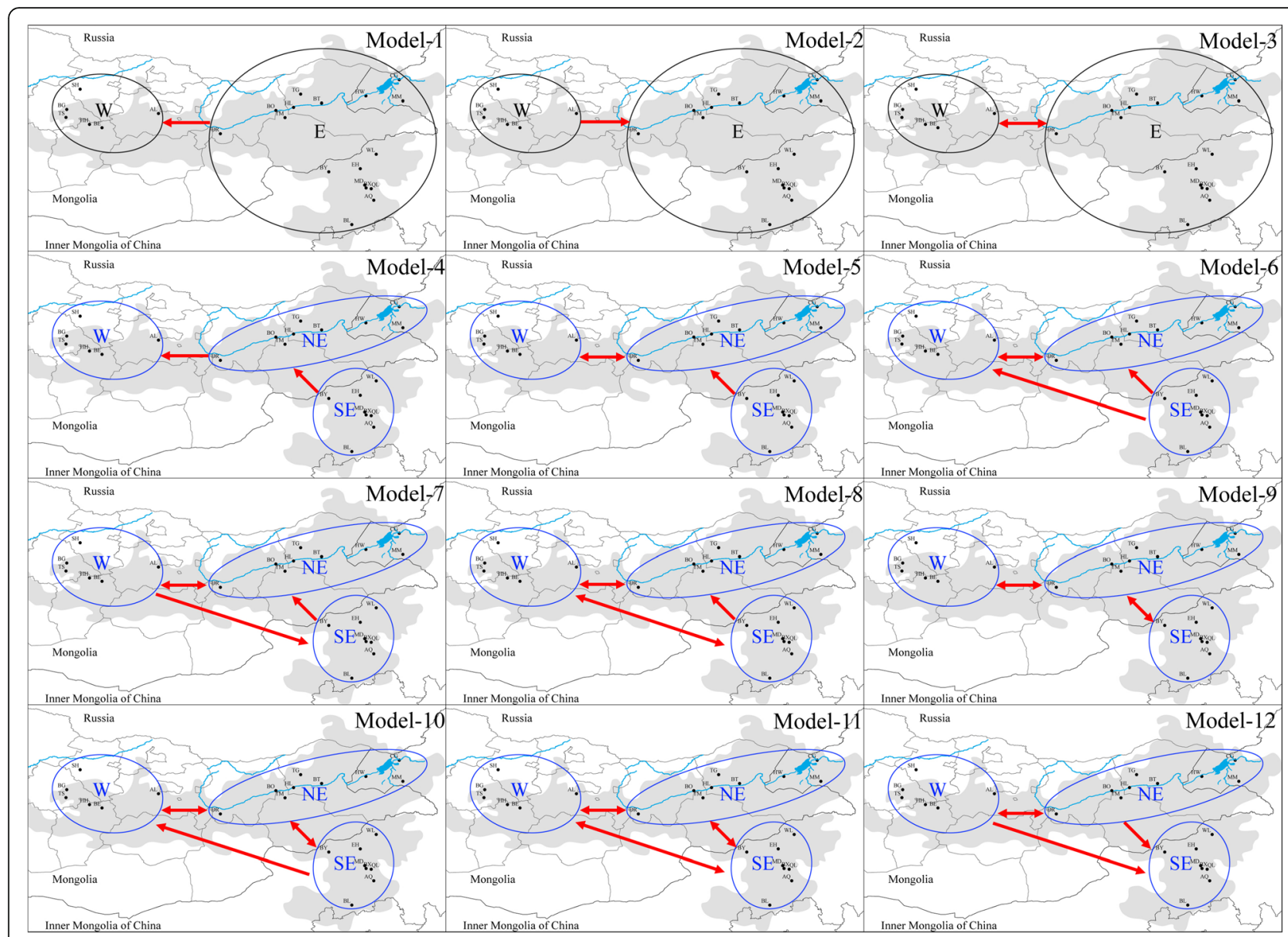

Fig. 4 Full set of migration models (model 1-12) conceived and tested using microsatellite data simulate in the program MIGRATE-N. W, West; E, East; NE, Northeast; and SE, Southeast

Table 3 Marginal log-likelihoods and model probabilities for 15 migration models (Fig. 4) among two and three clusters using microsatellite data in Brandt's vole

\begin{tabular}{|c|c|c|c|c|c|c|c|}
\hline Regions & Number of samplings & Model & Bezier ImL & Harmonic ImL & Raw score & Mean ImL & Model probabilities \\
\hline \multirow[t]{3}{*}{2 regions } & $5 \times 10^{7}$ & Model 1 & $-57,349.74$ & -1145.72 & $-316,290.09$ & $-124,928.52$ & 1 \\
\hline & & Model 2 & $-63,735.82$ & -1364.26 & $-356,188.44$ & $-140,429.51$ & 0 \\
\hline & & Model 3 & $-58,542.1$ & -1228.6 & $-335,142.1$ & $-131,637.6$ & 0 \\
\hline \multirow[t]{9}{*}{3 regions } & $5 \times 10^{7}$ & Model 4 & $-49,419.84$ & -1265.02 & $-262,401.1$ & $-104,361.99$ & 1 \\
\hline & & Model 5 & $-50,478.96$ & -1223.96 & $-269,783.24$ & $-107,162.05$ & 0 \\
\hline & & Model 6 & $-54,431.6$ & -993.38 & $-294,577.04$ & $-116,667.34$ & 0 \\
\hline & & Model 7 & $-104,545.89$ & -1052.16 & $-607,229.48$ & $-237,609.18$ & 0 \\
\hline & & Model 8 & $-118,766.8$ & -718.94 & $-696,727.88$ & $-272,071.21$ & 0 \\
\hline & & Model 9 & $-172,482.06$ & -831.40 & $-1,032,522.62$ & $-401,945.36$ & 0 \\
\hline & & Model 10 & $-108,659.74$ & -619.15 & $-634,189.74$ & $-247,822.88$ & 0 \\
\hline & & Model 11 & $-1,683,126.9$ & -512.63 & $-276,531.64$ & $-653,390.38$ & 0 \\
\hline & & Model 12 & $-94,635.4$ & -878.16 & $-545,702.85$ & $-213,738.8$ & 0 \\
\hline
\end{tabular}




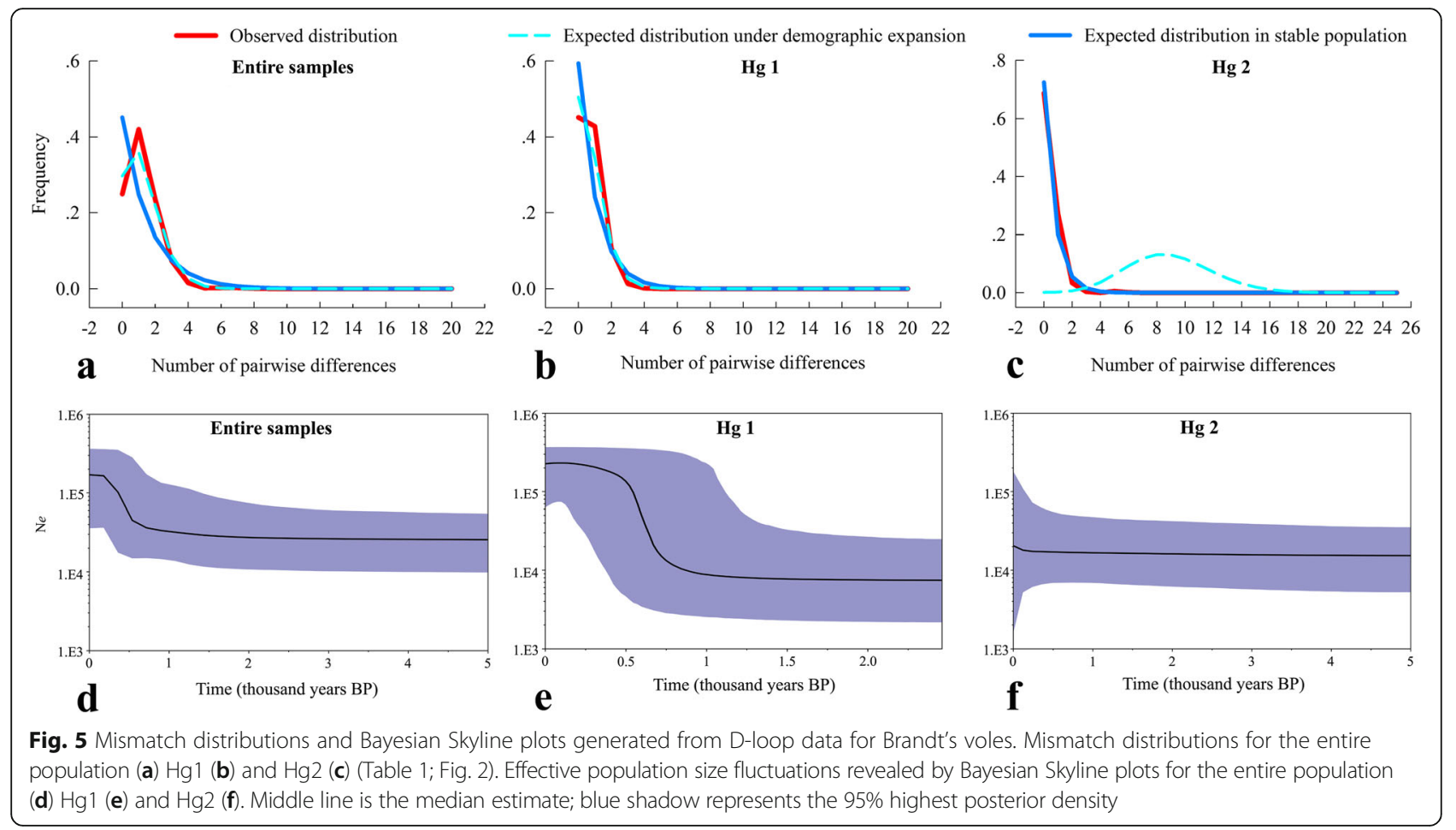

Average of $F_{S T}$ values computed for the microsatellite data between sampling sites from the southeastern, northeastern and western range of the species varied, 0.042 (range 0.015-0.1), 0.044 (0.025-0.099), and 0.059 (0.023-0.099), respectively (Additional file 1 : Table S7). $F_{S T} /\left(1-F_{S T}\right)$ and geographical distances (lnGD) were significantly correlated for the microsatellite dataset from entire samples $\left(R^{2}=0.149, P<0.0001\right)$, which is consistent with IBD. Significant IBD was supported for the eastern samples if analyzed separately $\left(R^{2}=0.045\right.$, $P=0.021$ ), but was not significant for samples from the western samples $\left(\mathrm{R}^{2}=0.0645, P=0.265\right)$. If we considered three, rather than two, regional genetically split populations none of the IBD analyses emerged as significant (southeast: $\mathrm{R}^{2}=0.068, P=0.126$; northeast: $R^{2}=0.033, P=0.354$; west: $R^{2}=0.0645$, $P=0.265)$ (Fig. 6).

Analysis of microsatellite data divided Brandt's voles population into three clusters from southeastern, northeastern and western of its current distribution (Fig. 1b). Using this population structure and patterns of migration and population expansion we posited the hypothesis that the conditions were in place for gene surfing to have occurred in this species.

We obtained six sets of average $F_{\mathrm{ST}}$ values between one site samples in a cluster and the samples from each site in another cluster. ANOVA results revealed that BX population in the southeastern region had the significantly lowest value relative to all of the site samples in the northeastern region. Similar calculations revealed that the obviously lowest average $F_{\mathrm{ST}}$ was obtained for $\mathrm{BT}$ from the northeastern to the southeastern, $\mathrm{BO}$ from the northeastern to the western, AL from the western to both the northeastern and the southeastern, and BX had the lowest average $F_{\mathrm{ST}}$ from the southeastern to the western, although this value was not significant (Fig. 7). Based on the combination of the above-discribed results corresponding to the lowest average $F_{\mathrm{ST}}$ (Fig. 7) and genetic characteristics (Additional file 1: Table S3), we hypothesized that BX and BT were the starting and arrival sites of the population spreading from the southeasterm to the northeastern and that $\mathrm{BO}$ and $\mathrm{AL}$ were the starting and arrival sites of the population spreading from the northeastern to the western, even though BO did not present the highest genetic diversity.

In the three regions, the allelic richness $\left(A_{r}\right)$ and expected heterozygosity $\left(H_{e}\right)$ significantly decreased with increasing $F_{\mathrm{ST}}$ values to the probable start or arrival site with the expection of the starting site of $\mathrm{BO}$ in the northeastern (Fig. 8). Nine of all allele frequencies for samples from each site in the western significantly varied in relation to their $F_{\mathrm{ST}}$ to the arrival site AL (six decreased and three increased). Seven and five allele frequencies showed significant variations with increasing $F_{\mathrm{ST}}$ values to the probable arrival site $\mathrm{BT}$ and the starting site $\mathrm{BO}$ in the northeastern, respectively. In the southeastern, eight allele frequencies were significantly correlated with the $F_{\mathrm{ST}}$ to $\mathrm{BX}$ (Table 4). More clinal patterns of allele frequencies were observed in the colonization from the northeastern to the western but not in the 

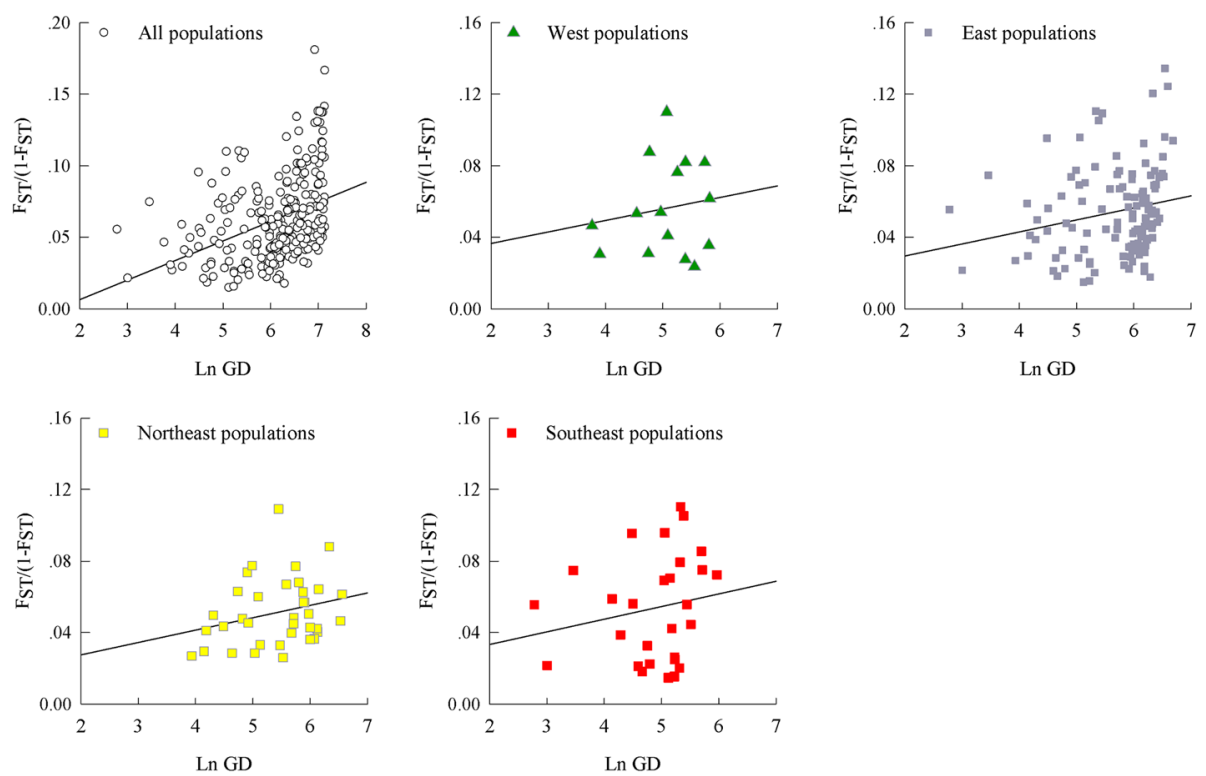

Fig. 6 Tests of isolation by distance (IBD) analyses for each cluster (Fig. 1b) of Brandt's vole using microsatellite data. The genetic distance measure $F_{S T}-\left(1-F_{S T}\right)$ was plotted against the geographic distance measure ( $L n G D$, measured in $k m$ )

expansion from the southeastern to the northeastern, which possibly resulted from the bridge status of the northeastern. Surprisingly, some alleles that were found to be rare in the sampling sites in southeastern and northeastern ranges showed high frequencies in some sites within the northeastern and western, respectively (Additional file 3: Table S9).

\section{Discussion}

Brandt's vole is a species of Lasiopodomys that was recently separated from the genus Microtus [93]. The species has some peculiar biological and ecological characteristics, i.e., seasonal and multi-annual population fluctuations $[17,18]$ and the discrete and homogeneous habitat environment. Our work described here is an attempt to re-construct the geographic origin of the species in current distribution and subsequent events that led to the present-day distribution of the species. In addition, during this study the phenomenon of genetic surfing emerged as a possible explanation for the peculiar patterns of genetic differentiation, and the success of genetic lineages.

\section{Ancestral area of Brandt's vole}

Phylogeographic and STRUCTURE analysis of microsatellite data and D-loop sequences revealed that Brandt's vole currently is comprised out of two to three genetically differentiated populations (Figs. 2 and $3 \mathrm{~b}$ ). To refer to the spatial structuring of the species we refer to these as eastern and western clusters (two symbols in Figs. 1b and $3 \mathrm{c}$ ), or if we consider are more refined structuring we refer to these as southeastern, northeastern and western clusters (two symbols in Figs. 1b and 3c). We used the three clusters in the analyses of origination and colonization route, the southeastern cluster presented the maximum probability ancestry $(P=63.5 \%$ for S-DIVA and $P=0.76$ for DEC) of the most primitive ancestral haplotype inferred by RASP and Lagrange (Fig. 3d; Additional file 3: Table S9). These results strongly supported the southeastern region (specifically Xilinhaote District, Inner Mongolia of China) as being the ancestral location of Brandt's vole prior to its expansion (Fig. 3c). This coincides with the pleistocene fossil evidence observed in northern China [10].

\section{Range expansion of Brandt's vole}

Neutral tests (Table 1), mismatch analysis (Fig. 5) and MJ network (Fig. 3b; Additional file 1: Table S5) of D-loop sequences indicating a past rapid expansion of the population of Brandt's vole from a few founders [83, 89, 94, 95]. The diversity values (Table 1), mismatch distributions (Fig. 5b \& c) and BSP (Fig. 5e \& f) revealed that $\mathrm{Hg} 2$ expanded later than $\mathrm{Hg} 1$, with the temporal scale and spatial scope essentially agreeing with the optimal colonization route, which was from the ancestral area (the southeastern) to the western through the northeastern (Fig. 4). These findings supported a scenario where a small number of founders disperse and initiate colonization followed by a rapid population expansion [80]. Pleistocene fossils of the species further indicate that its previous distribution was wider than the current one [10]. Thus, the molecular data and the 

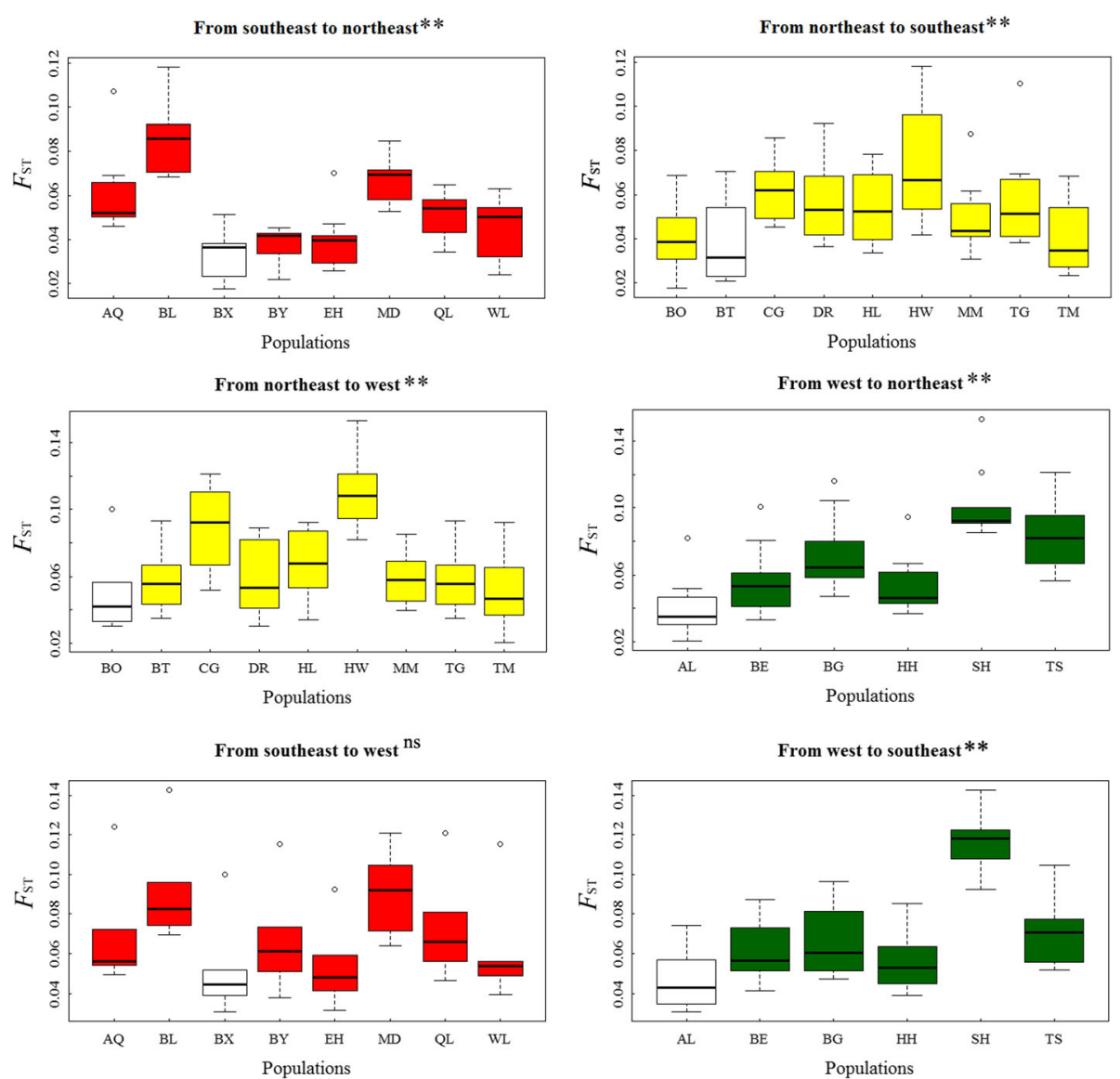

Fig. 7 Pairwise $F_{\text {ST }}$ values between each samples obtained from one site that is part of a cluster (c.f. Fig. 1b) and all samples from all sites from another cluster and estimated these values in a pairwise manner for the three clusters. The white column presents the population with the lowest average $F_{S T}$ within the corresponding cluster, which is considered the likely starting or arrival site of Brandt's vole. Population abbreviations as in Fig. 1b (ns: $P>0.05, *: P<0.05, * *: P<0.01$ )

fossil evidence remain to be reconciled, the fact that the past distribution was wider than the present distribution implies that the populations spread from their initial location.

Range expansion can be viewed as a series of successive founder events [88] that result in a decrease in intrademe heterozygosity with increasing distance from the ancestral population to other demes within a region [88-91]. The IBD for all Brandt's vole populations showed that the population expansion generally satisfied the one-dimensional stepping-stone model $\left(R^{2}=0.149\right.$, $P<0.0001)$ [85]. However, none of the regressions for the southeastern, northeastern and western were significant, which suggests the possible existence of geographic barriers or a greatly heterogeneous environment. Therefore, we used pairwise $F_{\mathrm{ST}}$ values instead of the geographical distance to test the range expansion of Brandt's vole. The results that the $H_{e}$ values significantly decrease with increasing $F_{\mathrm{ST}}$ values to the probable arrival (BT and $\mathrm{AL}$ ) or starting (BX and $\mathrm{BO}$ ) sites for the species (Fig. 8) supported the hypothesis of range expansion.

The fossil evidence indicates that Lasiopodomys was present in the late Early Pleistocene [10]. We inferred the expansion time of L.brandtii happed earlier than 0.041 Mya (about middle-late Pleistocene), which is for the species' diversion into Hg1 clade (Fig. 2). In this period, the climate changed towards cooler and more arid, causing land degeneration and desertification $[28,29]$, big area of meadow-steppes degenerated gradually into the dry steppes and semi-deserts in Mongolia $[3,10,96]$, where were favourable habitats for Brandt's voles. That might have promoted the dispersal and increase in the species populations over time [17, 24]. Towards the Holocene, the climate gradually became mild, resulting expanding forest in the west and central Mongolia [25] and the Transbaikal plains, Russia [10]. As a result, the suitable habitats of Brandt's vole significantly decreased. The changes would destroy some preferred habitats of Brandt's vole and cause fragmentation and 

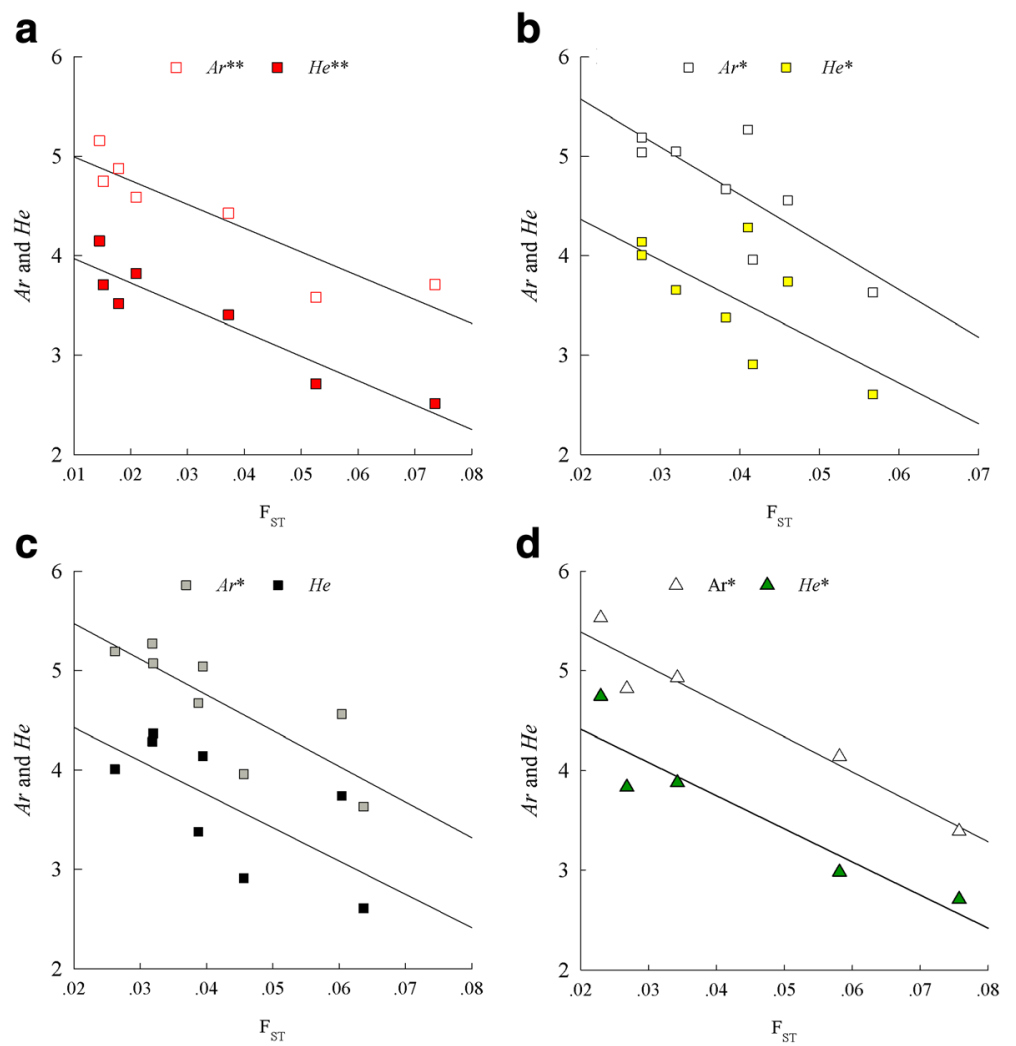

Fig. 8 Regression of the allelic richness $\left(A_{r}\right)$ and expected heterozygosity $\left(H_{e}\right)$ of samples obtained from one site in a cluster (for clusters c.f. Fig. 1b) against $F_{\text {ST }}$ values to the corresponding arrival or starting site (Fig. 7). Regressions are shown in a for each site samples in the southeastern cluster with regard to BX. $\mathbf{b}$ for each site samples in the northeastern cluster with BT. $\mathbf{c}$ for each site samples in the northeastern cluster with BO. $\mathbf{d}$ for each site samples in the western cluster with AL. (ns: ${ }^{*} P<0.05,{ }^{* *} P<0.01$ )

reduction in their distribution [97], which possibly contributed to the differences between the populations from the original and colonized regions.

\section{Genetic surfing in Brandt's vole population}

Prior to this study, the genetic dynamics in range expansions have mostly been based on modeling, simulations and microcosm experiments and have not been corroborated using field data. In accordance with the colonization route of Brandt's vole from the southeastern to the western through the northeastern, the neutral genetic pattern of the population matches the predictions of the genetic surfing theory:

1. A steady reduction in genetic diversity with increasing $F_{\mathrm{ST}}$ to the starting site centroid (BX and $\mathrm{BO}$ ) or the probable arrival site centroid (BT and $\mathrm{AL}$ ) within each of the three regions (Fig. 8) [87].

2. The alleles present on the wave front of an expansion could increase in frequency and reach very high proportions and even fixations far away from their original areas [39, 98, 99], and this change is particularly observed in the frequencies of rare alleles
[100]. In the surveyed Brandt's vole populations, some rare alleles in both the southeastern and the northeastern have become common in the corresponding expansion ranges, namely the northeastern and western (Additional file 3: Table S9). Additionally, more clinal patterns of allele frequencies involving different loci are found in the colonized areas compared with the original areas (Table 4), although this difference is not significant.

3. The spatial differentiation is stronger in the more recently established range than in the original one [101], and this finding is also supported by the mean pairwise $F_{\mathrm{ST}}$ values within each region calculated from microsatellite data, which were found to equal 0.042 , 0.044 and 0.059 for the western, southeastern and northeastern, respectively (Additional file 1: Table S7).

Genetic drift acting on the advancing front could cause the extant spatial genetic patterns of Brandt's vole during its expansion within the distribution. Some individuals, particularly those in an outbreak population, possibly disperse outward from the original habitat due to intraspecific competition. These voles were likely the 
Table 4 Allele frequencies showing spatial clines in southeast, northeast and west clusters

\begin{tabular}{|c|c|c|c|c|c|c|c|c|c|}
\hline \multirow[t]{2}{*}{ Locus } & \multirow[t]{2}{*}{ allele } & \multicolumn{2}{|c|}{ Southeastern (BX) } & \multicolumn{2}{|c|}{ Northeastern (BT) } & \multicolumn{2}{|c|}{ Northeastern (BO) } & \multicolumn{2}{|c|}{ Western (AL) } \\
\hline & & frequency & $\begin{array}{l}\text { spatial correlation } \\
\left(R^{2}\right)\end{array}$ & frequency & $\begin{array}{l}\text { spatial correlation } \\
\left(R^{2}\right)\end{array}$ & frequency & $\begin{array}{l}\text { spatial correlation } \\
\left(R^{2}\right)\end{array}$ & frequency & $\begin{array}{l}\text { spatial correlation } \\
\left(R^{2}\right)\end{array}$ \\
\hline \multirow[t]{2}{*}{ DQ886928 } & 183 & 0.311 & n.s. & 0.175 & n.s. & 0.175 & n.s. & 0.303 & $-0.738^{*}$ \\
\hline & 185 & 0.140 & n.s. & 0.111 & $0.725^{*}$ & 0.111 & n.s. & 0.118 & n.s. \\
\hline \multirow[t]{2}{*}{ FJ538254 } & 258 & 0.457 & $0.68^{*}$ & 0.344 & n.s. & 0.344 & n.s. & 0.388 & n.s. \\
\hline & 268 & 0.067 & $-0.828^{* *}$ & 0.105 & n.s. & 0.105 & n.s. & 0.055 & $-0.889^{*}$ \\
\hline DQ886926 & 141 & 0.397 & n.s. & 0.289 & n.s. & 0.289 & $0.589^{*}$ & 0.462 & $-0.893^{*}$ \\
\hline DQ886929 & 177 & 0.537 & n.s. & 0.644 & n.s. & 0.644 & n.s. & 0.526 & $0.821^{*}$ \\
\hline \multirow[t]{2}{*}{ DQ886927 } & 152 & 0.309 & n.s. & 0.416 & $-0.506^{*}$ & 0.416 & n.s. & 0.291 & n.s. \\
\hline & 182 & 0.081 & n.s. & 0.084 & $0.698^{* *}$ & 0.084 & $0.541^{*}$ & 0.062 & n.s. \\
\hline \multirow[t]{3}{*}{ DQ886925 } & 164 & 0.633 & $-0.811^{* *}$ & 0.246 & $0.45^{*}$ & 0.246 & n.s. & 0.585 & $0.95^{* *}$ \\
\hline & 168 & 0.191 & $0.72^{*}$ & 0.099 & n.s. & 0.099 & n.s. & 0.161 & n.s. \\
\hline & 172 & 0.061 & n.s. & 0.011 & n.s. & 0.011 & n.s. & 0.093 & $0.729 * *$ \\
\hline FJ538255 & 248 & 0.016 & $0.742^{*}$ & 0.047 & n.s. & 0.047 & n.s. & 0.007 & n.s. \\
\hline \multirow[t]{5}{*}{ DQ886933 } & 162 & 0.014 & n.s. & 0.045 & n.s. & 0.045 & n.s. & 0.030 & $-0.894^{*}$ \\
\hline & 170 & 0.107 & $0.572^{*}$ & 0.075 & n.s. & 0.075 & n.s. & 0.022 & $-0.72^{*}$ \\
\hline & 172 & 0.307 & $0.85^{* *}$ & 0.049 & n.s. & 0.049 & n.s. & 0.186 & n.s. \\
\hline & 174 & 0.084 & n.s. & 0.084 & $-0.48^{*}$ & 0.084 & n.s. & 0.145 & n.s. \\
\hline & 186 & 0.048 & n.s. & 0.063 & n.s. & 0.063 & $-0.518^{*}$ & 0.089 & n.s. \\
\hline DQ886931 & 219 & 0.145 & n.s. & 0.124 & n.s. & 0.124 & $0.516^{*}$ & 0.220 & $-0.764^{*}$ \\
\hline \multirow[t]{2}{*}{ FJ538252 } & 296 & 0.439 & n.s. & 0.431 & $0.716^{* *}$ & 0.431 & n.s. & 0.258 & n.s. \\
\hline & 300 & 0.210 & $0.637^{*}$ & 0.233 & $-0.676^{*}$ & 0.233 & $-0.663^{*}$ & 0.248 & n.s. \\
\hline
\end{tabular}

Southeast allele frequencies were correlated with $F_{\mathrm{ST}}$ to the putative starting site (BX), while northeast allele frequencies were correlated with $F_{\mathrm{ST}}$ to the probable arrival site (BT); northeast and west allele frequencies were correlated with $F_{\mathrm{ST}}$ values to the starting site $(\mathrm{BO})$ and the arrival site $(\mathrm{AL})$, respectively (ns: $P>0.05$, *: $\left.P<0.05,{ }^{* *}: P<0.01\right)$

pioneers in the new habitats. Such dispersal can lead to large gene frequency changes and can determine the genetic diversity of colonies propagated by aggressors [101], as was typically observed in the populations from $\mathrm{BX}$ in the southeastern to BT in the northeastern, and from $\mathrm{BO}$ in the northeastern to AL in the western (Fig. 1b). Consequently, this distribution would lead to increased global genetic differentiation and strengthen the presence of migration among populations $[91,99,101,102]$. These patterns are also supported by the results of genetic structure analysis (Fig. 1; Table 2) and the most likely migration models (Fig. 5; Table 3) inferred from microsatellite data.

The spatial genetic patterns of Brandt's vole populations are unlikely to have been produced by two important alternative scenarios: adaptive events generated by selective sweeps [27, 103] and introgression [104, 105]. For example, clines in allele frequency are often attributed to geographic variations in selection intensity [91]. Although Brandt's vole distribution was composed of many patchy homogeneous habitats [20], the geographic variation in selection intensity was low. Genetic patterns such as gradients of introgression $[104,105]$ or bidirectional introgression close to the introduction area of an invasive species are often interpreted as footprints of selection [27]. Introgression generally occurs in inter-divergent geographical populations, and the divergence level of the two/three clusters in Brandt's vole population did not support the taxonomy of subspecies (Fig. 1a).

A combination of demographic properties including population size, growth rate and migration rate, determines the success of mutations in populations under range expansion $[39,106,107]$. Our results illustrate the existence of the surfing phenomenon during Brandt's vole range expansion, but the demographic properties of the successful colonized populations, such as the populations around $\mathrm{BX}$ and $\mathrm{BO}$ sites, require further investigation. Otherwise, the heterogeneous landscape might play an important role in determining the fate of mutations, such as their locations $[108,109]$. It is undoubtedly more complex than corroborating the effects of these processes in natural populations.

\section{Hypothesis of colonization pattern in Brandt's vole}

In a patch structure of an environment, the habitat types selected by individuals should be a combined result of the intrinsic "quality" of the habitat type and the population 
density (intensity of competition) in the habitat [110, 111]. Population outbreaks of Brandt's voles occur irregularly, with an interval of five to seven years [17, 18]. Based on repetitions of this pattern of spatial change throughout history, an outbreak population with opportunistic demographic properties, i.e., suitable population size, growth rate and migration rate, inhabiting the surroundings of the BX site located in the current southeastern distribution was expanding spatially. Some "excess" individuals arrived and successfully settled in a new habitat in the area surrounding the BT site, which was never previously occupied by the species and that is equal in quality to the original habitat. These settlers acted as a seed for the population colonizing the new territories located in the current northeastern distribution. Similar processes occurred during the colonization from $\mathrm{BO}$ site in the northeastern to AL site in the western (Fig. 1c) and perhaps further westward until Brandt's vole population covered the whole distribution area. Such expansion processes can lead to the spatial patterns of genetic structure coinciding with the traits of the genetic surfing phenomenon $[39,101,112]$. Our results from genetic data match the predictions made based on the genetic surfing theory.

\section{Conclusions}

We hypothesized that Brandt's voles originated from the extant southeastern distribution. Under the integrative effect of various factors, such as temperature, rainfall, vegetation and landscape traits, this species colonized from the original area surrounding BX in Xilinguole region, propagating by wave within the region to reach the probable arrival site BT in the northeastern and expanding thereafter within the area; the subsequent expansion of Brandt's voles population to the western at the arrival site AL from the starting site BO in the northeastern followed the same surfing pattern. Landscape heterogeneity, a low density of individuals in the front of the wave and a low dispersal capacity promote the strong genetic structuration of the three clusters. Brandt's vole thus formed the current patterns, which are characterized by isolated, patchy, unstable habitats with some genetic characteristics.

\section{Additional files}

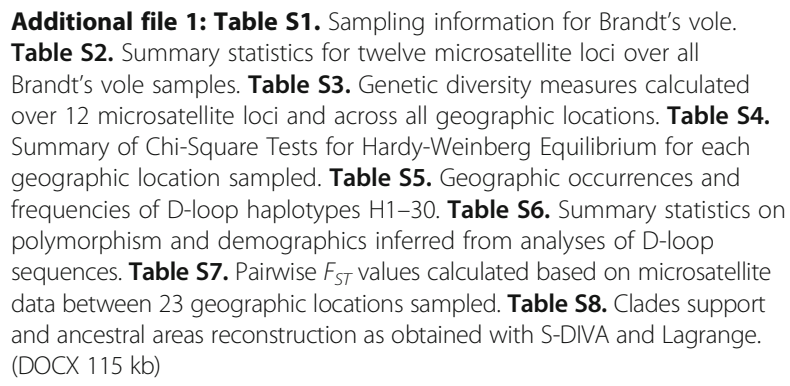

Additional file 2: Figure S1. Brandt's vole population structure based on 12 microsatellites loci as implemented by STRUCTURE. A) Values of $\ln P(D)$ from 20 independent runs for $K=1-23$. B) Values of $\Delta K$ from 20 independent runs plotted for $K=1-23$ and calculated by the Evanno method. (PDF $3121 \mathrm{~kb}$ )

Additional file 3: Table S9. A) Allele frenquency of each locus for Brandt's vole populations in southeastern and northeastern distribution; B) Allele frenquency of each locus for Brandt's vole populations in northeastern and western distribution. (XLSX $62 \mathrm{~kb}$ )

\section{Acknowledgements}

We thank Yi Jin, Wurenqimuge, Subuda (Inner Mongolia Agricultural University, China), Enkhbold Nanj and Nyamdorj Batsaikhan (Mongolian State University of Agriculture, Mongolia) for providing assistance with the field trap investigations; Dr. Marcel Holyoak (University of California, Davis, U.S.A.) and Dr. Ying Song (Institute of Plant Protection, CAAC) for providing comments on an earlier version of this manuscript.

\section{Avaliability of data and materials}

D-loop haplotype sequences from Brandt's voles were submitted to GenBank $^{\oplus}$ : Accession nos. KY354521-KY354550. Additional analyses are also provided as supporting information were deposited in GenBank.

\section{Funding}

This work was supported by International Science \& Technology Cooperation Program of China (2014DFG31760) and the National Natural Science Foundation of China $(31,371,955 ; 30,800,727)$

\section{Authors' contributions}

DW and KL conceived the experiments. DW, DZS and XRW contributed samples. $\mathrm{KL}, \mathrm{SMZ}$ and $\mathrm{DW}$ conducted the experiments. $\mathrm{KL}$ and $\mathrm{DW}$ analysed the data. KL, DW and M.H.K wrote the manuscript. All authors read and approved the final manuscript.

\section{Competing interests}

The authors declare that they have no competing interests.

Consent for publication

Not applicable.

\section{Ethics approval}

Permission to trap animals was approved by the Animal Care \& Welfare Committee of China Agricultural University (CAU20080823-1).

\section{Publisher's Note}

Springer Nature remains neutral with regard to jurisdictional claims in published maps and institutional affiliations.

\section{Author details}

${ }^{1}$ College of Plant Protection, China Agricultural University, 2 Yuanmingyuan West Road, Haidian District, Beijing 100193, China. ${ }^{2}$ Institute of Biosciences and Bioengineering, Rice University, 130 Anderson Biology, P.O. Box 1892, Houston 77251-1892, USA. ${ }^{3}$ State Key Laboratory for Integrated Management of Pest Insects and Rodents, Institute of Zoology, Chinese Academy of Sciences, 1 Beichen West Road, Chaoyang District, Beijing 100101, China.

Received: 9 March 2017 Accepted: 7 June 2017

Published online: 21 June 2017

References

1. Hewitt GM. Some genetic consequences of ice ages, and their role in divergence and speciation. Biol J Linn Soc. 1996;58(3):247-76.

2. Hewitt GM. The genetic legacy of the Quaternary ice ages. Nature. 2000;405:907-13.

3. Petrova TV, Zakharov ES, Samiya R, Abramson NI. Phylogeography of the narrow-headed vole Lasiopodomys (Stenocranius) gregalis (Cricetidae, Rodentia) inferred from mitochondrial cytochrome b sequences: an echo of Pleistocene prosperity. J Zool Syst Evol Res. 2015;53(2):97-108. 
4. Brunhoff C, Galbreath KE, Fedorov VB, Cook JA, Jaarola M. Holarctic phylogeography of the root vole (Microtus oeconomus): implications for late Quaternary biogeography of high latitudes. Mol Ecol. 2003;12(4):957-68.

5. Runck AM, Cook JA. Postglacial expansion of the southern red-backed vole (Clethrionomys gapperi) in North America. Mol Ecol. 2005;14(5):1445-56.

6. Heckel G, Burri R, Fink S, Desmet JF, Excoffier L. Genetic structure and colonization processes in European populations of the common vole. Microtus arvalis Evolution. 2005;59(10):2231-42.

7. Abramson NI, Petrova TV, Dokuchaev NE, Obolenskaya EV, Lissovsky AA. Phylogeography of the grey red-backed vole Craseomys rufocanus (Rodentia: (ricetidae) across the distribution range inferred from nonrecombining molecular markers. Russian Journal of Theriology. 2012;11(2):137-56.

8. Prost S, Guralnick RP, Waltari E, Fedorov VB, Kuzmina E, Smirnov N, et al. Losing ground: past history and future fate of Arctic small mammals in a changing climate. Glob Chang Biol. 2013;19(6):1854-64.

9. Shenbrot GI, Krasnov BR. Atlas of the geographic distribution of the arvicoline rodents of the world (Rodentia, Muridae: Arvicolinae). Moscow: Pensoft Press; 2005.

10. Alexeeva N, Erbajeva M, Khenzykhenova F. Lasiopodomys brandtii In Pleistocene of Transbaiklia and adjacent territories: distribution area, evolutionary development in context of global and regional events. Quat Int. 2015;355:11-7.

11. Lyapunova EA, Mirokhanov YM. Description of the Field Vole Chromosome Sets (Stenocranius, Lasiopodomus, Blanfordimus, Microtus). Materialy II Vses. sov. po mlekopitayushchim,1969; 134-138.

12. Chaline J. Les rongeurs du pléistocène moyen et supérieur de France (systématique- biostratigraphie- paléoclimatologie). Cahiers de paléontologie. 1972;

13. Erbajeva MA, Sotnikova MV, Shevtchenko VK. New Eopleistocene locality of mammal fauna in Transbaikalia. Paleontological Foundation of the Anthropogene Stratigraphy, Moscow. 1977;103

14. Agadzhanyan AK, Yatsenko VN. Phylogenetic interrelationships in voles of northern Eurasia. Archives of Zoological Museum of Moscow State University. 1984;22:135-90. (in Russian)

15. Abramson NI, Golenishchev FN, Kostygov AY, Tesakov AS. Taxonomic interpretation of the molecular-genetic cladogram of tribe Microtini (Arvicolinae, Rodentia) based on nuclear genes. In: Materials of the International Meeting "Theriofauna of Russia and Adjacent Areas". 2011; 1e4, Moscow, 7 (in Russian).

16. Zhong WQ, Zhou QQ, Sun CL. The basic characteristics of the rodent pests on the pasture in Inner Mongolia and the ecological strategies of controlling. Acta Theriologica Sinica. 1985;5:241-9. (in Chinese)

17. Zhang ZB, Pech R, Davis S, Shi DZ, Wan XR, Zhong WQ. Extrinsic and intrinsic factors determine the eruptive dynamics of Brandt's voles. Microtus brandti in Inner Mongolia, China. Oikos. 2003a;100:299-310.

18. Li ZL, Liu TC. Population cycle of Brandt's vole (Microtus brandti) and rodent community succession in Xilingele-Meng. Zoology Research. 1999;20:284-7. (in Chinese)

19. Wang WG, Wu HS, Chen SK, Gao HB. Rodent and damages. Control of grassland pests in Hulunbeir, China, China Agricultural Press. 2005:98-101. (in Chinese)

20. Jiang YE, Enkhbold N, Batsaikhan N, Wang D, Yi J. Wurenqimuge, Shan LY, du GL, Shi D. Study on the habitat characteristics of Brandt's vole. Acta Agrestia Sinica. 2012;20(2):179-82. (in Chinese)

21. Zhong WQ, Wang MJ, Wan XR. Ecological management of Brandt's vole (Microtus brandti) in Inner Mongolia, China. In: Singleton GR, Hinds LA, Leirs $H$, Zhang Z, editors. Ecologically-based management of rodent pests. Canberra: ACIAR Monograph. Australian Centre for International Agricultural Research; 1999. p. 199-214.

22. Zhong WQ, Zhou QQ, Wang GH, Sun CL, Zhou PL, Liu WZ, et al. The design for the ecological management of Brandt's vole pest and its application. Acta Theriologica Sinica. 1991;11:204-12. (in Chinese)

23. Luo TS, Hao SS, Liang ZA, Niu DF, Zao HC. Some biological observations of the Brandt's vole (Microtus brandti Radde) control in Hulun-Beier grassland. Acta Zool Sin. 1975;21:5-61. (in Chinese)

24. Zhang ZB, Zhong WQ, Fan NC. Rodent problems and management in the grasslands of China. ACIAR Monograph series. 2003b;96:316-9.

25. An CB, Chen FH, Barton L. Holocene environmental changes in Mongolia: a review. Glob Planet Chang. 2008;63(4):283-9.

26. Lehmkuhl F, Hilgers A, Fries $S$, Hülle $D$, Schlütz F, Shumilovskikh $L$, et al. Holocene geomorphological processes and soil development as indicator for environmental change around Karakorum, upper Orkhon Valley (Central Mongolia). Catena. 2011;87(1):31-44.

27. Excoffier L, Foll M, Petit RJ. Genetic consequences of range expansions. Annu Rev Ecol Evol Syst. 2009:40:481-501.

28. Li JH, Pan HW, Wang G. Degradation causes of typical steppe in Inner Mongolia. Pratacultural Scientia. 2004;21:49-51. (In Chinese)

29. Li SY, Li XB, Wang DD. Prediction of grassland degradation in Xilinhaote of Inner Mongolia based on Markov process model. Chinese Journal of Ecology. 2007;26:78-82. (In Chinese)

30. Natsagdorj L, Dulamsuren J. Some aspect of assessment of the dzud phenomena. Papers in Institute of Meteorology and Hydrology. 2001;23(3):3-18.

31. Hoshino B, Ganzorig S, Sawamukai M, Kawashima K, Baba K, Kai K, Nurtazin S. The impact of land cover change on patterns of zoogeomorphological influence: Case study of zoogeomorphic activity of Microtus brandti and its role in degradation of Mongolian steppe. In 2014 IEEE Geoscience and Remote Sensing Symposium. 2014; 3518-3521.

32. Zhang C, Zhang W, Feng Z, Mischke S, Gao X, Gao D, et al. Holocene hydrological and climatic change on the northern Mongolian plateau based on multi-proxy records from Lake gun Nuur. Palaeogeogr Palaeoclimatol Palaeoecol. 2012:323:75-86.

33. Liu H, Xu L, Cui H. Holocene history of desertification along the woodlandsteppe border in northern China. Quat Res. 2002;57(2):259-70.

34. Feng ZD. Gobi dynamics in the northern Mongolian plateau during the past 20,000+ yr: preliminary results. Quat Int. 2001;76:77-83.

35. Hancock AM, Witonsky DB, Gordon AS, Eshel G, Pritchard JK, Coop G, et al. Adaptations to climate in candidate genes for common metabolic disorders. PLoS Genetic. 2008:4(2):32.

36. Coop G, Pickrell JK, Novembre J, Kudaravalli S, Li J, Absher D, et al. The role of geography in human adaptation. PLoS Genetic. 2009;5(6):e1000500.

37. Novembre J, Di Rienzo A. Spatial patterns of variation due to natural selection in humans. Nat Rev Genet. 2009:10(11):745-55.

38. Storz JF, Wheat CW. Integrating evolutionary and functional approaches to infer adaptation at specific loci. Evolution. 2010;64(9):2489-509.

39. Klopfstein S, Currat M, Excoffier L. The fate of mutations surfing on the wave of a range expansion. Mol Biol Evol. 2006;23(3):482-90.

40. Wood MD, Slade NA. Comparison of ear-tagging and toe-clipping in prairie voles, Microtus Ochrogaster[J]. J Mammal. 1990;71(2):252-5.

41. Sambrook J, Fritsch EF, Maniatis T. Molecular cloning: a laboratory manual [M]. Cold spring harbor laboratory press. 1989;

42. Wang D, Shi DZ. Isolation and characterization of polymorphic microsatellite loci from Brandt's voles (Lasiopodomys brandtii). Mol Ecol Notes. 2007;7:671-3.

43. Yue L, Wang D, Huang B, Liu X. Characterization of nine novel microsatellite markers from Brandt's vole (Lasiopodomys brandtii). Mol Ecol Resour. 2009:9:1194-6.

44. Van OC, Hutchinson WF, Wills DPM, Shipley P. MICRO-CHECKER: software for identifying and correcting genotyping errors in microsatellite data. Mol Ecol Notes. 2004:4:535-8.

45. Valière N. GIMLET: a computer program for analysing genetic individual identification data. Mol Ecol Notes. 2002;2(3):377-9.

46. Lalitha S. Primer premier 5. Biotech Software \& Internet Report: The Computer Software Journal for Scient. 2000;1(6):270-2.

47. Burland TG. DNASTAR's Lasergene sequence analysis software. Bioinformatics Methods and Protocols. 1999;132:71-91.

48. Thompson JD, Higgins DG, Gibson TJ. CLUSTAL W: improving the sensitivity of progressive multiple sequence alignment through sequence weighting, position-specific gap penalties and weight matrix choice. Nucleic Acids Res. 1994;22:4673-80.

49. Raymond M, Rousset F. GENEPOP (version 1.2): population genetics software for exact tests and ecumenicism. J Hered. 1995:86:248-9.

50. Rice WR. Analyzing tables of statistical tests. Evolution. 1989;43:223-5.

51. Peakall R, Smouse PE. GenAIEx 6: genetic analysis in excel. Population genetic software for teaching and research. Mol Ecol Notes. 2006;6(1):288-95.

52. Kalinowski ST. The computer program STRUCTURE does not reliably identify the main genetic clusters within species: simulations and implications for human population structure. Heredity. 2011;106:625-32.

53. Takezaki N, Nei M, Tamura K. POPTREE2: software for constructing population trees from allele frequency data and computing other population statistics with windows interface. Mol Biol Evol. 2010;27(4):747-52.

54. Pritchard JK, Stephens M, Donnelly P. Inference of population structure using multilocus genotype data. Genetics. 2000;155:945-59. 
55. Earl D.A., vonHoldt B.M. STRUCTURE HARVESTER: a website and program for visualizing STRUCTURE output and implementing the Evanno method. 2012; 4: 359-361.

56. Evanno G, Regnaut $\mathrm{S}$, Goudet J. Detecting the number of clusters of individuals using the software STRUCTURE: a simulation study. Mol Ecol. 2005;14(8):2611-20.

57. Excoffier L, Laval G, Schneider S. Arlequin ver. 3.0: an integrated software package for population genetics data analysis. Evol Bioinformatics Online. 2005; 1:47-50.

58. Librado P, Rozas J. DnaSP v5: a software for comprehensive analysis of DNA polymorphism data. Bioinformatics. 2009;25:1451-2.

59. Drummond AJ, Suchard MA, Xie D, Rambaut A. Bayesian phylogenetics with BEAUti and the BEAST 1.7. Mol Biol Evol. 2012;29(8):1969-73.

60. MartíNková N, Moravec J. Multilocus phylogeny of arvicoline voles (Arvicolini, Rodentia) shows small tree terrace size[J]. Folia Zool. 2012;61(3/4):254

61. Lemskaya NA, Romanenko SA, Golenishchev FN, Rubtsova NV, Sablina OV, Serdukova NA, et al. Chromosomal evolution of Arvicolinae (Cricetidae, Rodentia). III. Karyotype relationships of ten Microtus species[]]. Chromosom Res. 2010;18(4):459-71.

62. Bužan EV, Kryštufek B, HÄNFLING B, Hutchinson WF. Mitochondrial phylogeny of Arvicolinae using comprehensive taxonomic sampling yields new insights[J]. Biol J Linn Soc. 2008;94(4):825-35.

63. Akaike H. A new look at the statistical model identification. IEEE Trans Autom Control. 1974;19:716-23.

64. Posada D, Crandall KA. MODELTEST: testing the model of DNA substitution. Bioinformatics. 1998;14:817-8.

65. Kass RE, Raftery AE. Bayes factors[]]. J Am Stat Assoc. 1995;90(430):773-95.

66. Drummond AJ, Rambaut A. BEAST: Bayesian evolutionary analysis by sampling trees. BMC Evolution Biology. 2007;7:214.

67. Rambaut A, Drummond AJ. Tracer v1.5, Available: http://beast.bio.ed.ac.uk/ Tracer. Accessed 2014 Jan 30. 2007.

68. Rambaut A. FigTree v1.3.1, Available from: http://tree.bio.ed.ac.uk/software/ figtree. 2009.

69. Bandelt $\mathrm{HJ}$, Forster $\mathrm{P}$, Rohl A. Median-joining networks for inferring intraspecific phylogenies. Mol Biol Evol. 1999;16:37-48.

70. ESRI (Environmental Systems Resource Institute). ArcMap 10.1. ESRI, Redlands, California. 2012

71. Yu Y, Harris AJ, He X. S-DIVA (statistical dispersal-Vicariance analysis): a tool for inferring biogeographic histories. Mol Phylogenet Evol. 2010;56:848-50

72. Yu Y, Harris AJ, He XJ. RASP (Reconstruct Ancestral State in Phylogenies) 2.1 beta. Available: http://mnh.scu.edu.cn/soft/blog/RASP. Access: 2014 Jan 30. 2013.

73. Ree R, Moore BR, Webb CO, Donoghue MT. A likelihood framework for inferring the evolution of geographic range on phylogenetic trees. Evolution. 2005;59:2299-311.

74. Ree RH, Smith SA. Maximum likelihood inference of geographic range evolution by dispersal, local extinction, and cladogenesis. Syst Biol. 2008:57:4-14.

75. Beerli P. Comparison of Bayesian and maximum likelihood inference of population genetic parameters. Bioinformatics. 2006;22:341-5.

76. Beerli P, Palczewski M. Unified framework to evaluate panmixia and migration direction among multiple sampling locations. Genetics. 2010;185:313-26

77. Kuhner MK. LAMARC 2.0: maximum likelihood and Bayesian estimation of population parameters. Bioinformatics. 2006;22:768-70.

78. Burnham KP, Anderson DR. Model selection and multimodel inference: a practical information-theoretic approach. Springer Science \& Business Media. 2003;

79. Fu Y, Li WH. Statistical tests of neutrality of mutations. Genetics. 1993;133: 693-709.

80. Fu Y. Statistical tests of neutrality of mutations against population growth, hitchhiking and background selection. Genetics. 1997;147:915-25.

81. Tajima F. Statistical method for testing the neutral mutation hypothesis by DNA polymorphism. Genetics. 1989;123:585-95.

82. Slatkin M, Hudson RR. Pairwise comparisons of mitochondrial DNA sequences in stable and exponentially growing populations. Genetics. 1991;129:555-62.

83. Rogers AR, Harpending H. Population growth makes waves in the distribution of pairwise genetic differences. Mol Biol Evol. 1992;9:552-69.

84. Wang Y, Zhao LM, Fang FJ, Liao JC, Liu NF. Intraspecific molecular phylogeny and phylogeography of the Meriones meridianus (Rodentia:
Cricetidae) complex in northern China reflect the processes of desertification and the Tianshan Mountains uplift [J]. Biol J Linn Soc. 2013;110(2):362-83.

85. Rousset F. Genetic differentiation and estimation of gene flow from $\mathrm{F}$ statistics under isolation by distance. Genetics. 1997;145:1219-28.

86. SPSS. SPSS advanced statistics 20.0. SPSS: Chicago, IL; 2011.

87. Graciá E, Botella F, Anadón JD, Edelaar P, Harris DJ, Giménez A. Surfing in tortoises? Empirical signs of genetic structuring owing to range expansion. Biol Lett. 2013;9(3):20121091.

88. Austerlitz F, Jung-Muller B, Godelle B, Gouyon PH. Evolution of coalescence times, genetic diversity and structure during colonization. Theor Popul Biol. 1997;51(2):148-64

89. Wegmann D, Currat M, Excoffier L. Molecular diversity after a range expansion in heterogeneous environments. Genetics. 2006;174(4):2009-20.

90. DeGiorgio M, Degnan JH, Rosenberg NA. Coalescencetime distributions in a serial founder model of human evolutionary history. Genetics. 2011;189:579-93.

91. Slatkin M, Excoffier L. Serial founder effects during range expansion: a spatial analog of genetic drift. Genetics. 2012;191:171-81.

92. Felauer T, Schlütz F, Murad W, Mischke S, Lehmkuhl F. Late Quaternary climate and landscape evolution in arid Central Asia: a multiproxy study of lake archive Bayan Tohomin Nuurç, Gobi desert, southern Mongolia. J Asian Earth Sci. 2012:48:125-35.

93. Luo ZX, Chen W, Gao W. Fauna Sinica Mammalia (Vol 6, Rodentia). Part III: Cricetidae. Science Press, Beijing; 2000. (in Chinese)

94. Li WH. Distribution of nucleotide differences between two randomly chosen cistrons in a finite population. Genetics. 1977:85:331-7.

95. Ray N, Currat M, Excoffier L. Intra-deme molecular diversity in spatially expanding populations. Mol Biol Evol. 2003;20(1):76-86.

96. Peck JA, Khosbayar P, Fowell SJ, Pearce RB, Ariunbileg S, Hansen BC, et al. Mid to late Holocene climate change in north central Mongolia as recorded in the sediments of Lake Telmen[J]. Palaeogeogr Palaeoclimatol Palaeoecol. 2002;183(1):135-53.

97. Wu ZJ, Li YM. Effects of habitat fragmentation on survival of animal populations. Acta Ecol Sin. 2003;23:2423-35. (In Chinese)

98. Travis JM, Münkemüller T, Burton OJ, Best A, Dytham C, Johst K. Deleterious mutations can surf to high densities on the wave front of an expanding population. Mol Biol Evol. 2007;24(10):2334-43.

99. Hallatschek O, Nelson DR. Life at the front of an expanding population. Evolution. 2009:64:193-206.

100. Hofer T, Ray N, Wegmann D, Excoffier L. Large allele frequency differences between human continental groups are more likely to have occurred by drift during range expansions than by selection. Ann Hum Genet. 2009;73(1):95-108.

101. Excoffier L, Ray N. Surfing during population expansions promotes genetic revolutions and structuration. Trends Ecol Evol. 2008;23(7):347-51.

102. Hallatschek O, Hersen P, Ramanathan S, Nelson DR. Genetic drift at expanding frontiers promotes gene segregation. Proc Natl Acad Sci. 2007;104:19926-30.

103. Currat M, Excoffier L, Maddison W, Otto SP, Ray N. Comment on "Ongoing adaptive evolution of ASPM, a brain size determinant in Homo sapiens" and "Microcephalin, a gene regulating brain size, continues to evolve adaptively in humans." Science 2006; 313: 172; author reply 72.

104. Rendine S, Piazza A, Cavalli-Sforza LL. Simulation and separation by principal components of multiple demic expansions in Europe. Am Nat. 1986;128:681-706

105. Currat $M$, Ruedi $M$, Petit RJ, Excoffier $L$. The hidden side of invasions: massive introgression by local genes. Evolution. 2008;62:1908-20.

106. Kimura M. On the probability of fixation of mutant genes in a population. Genetics. 1962;47:713-9.

107. Maruyama T. On the fixation probability of mutant genes in a subdivided population. Genet Res. 1970;15(2):221-5.

108. Burton OJ, Travis JM. The frequency of fitness peak shifts is increased at expanding range margins due to mutation surfing. Genetics. 2008a;179:941-50.

109. Burton OJ, Travis JM. Landscape structure and boundary effects determine the fate of mutations occurring during range expansions. Heredity. 2008b;101:329-40.

110. Fretwell SD, Lucas HL. On territorial behavior and other factors influencing habitat distribution in birds. Acta Biotheor. 1969;19:16-36.

111. Fretwell SD. Populations in a seasonal environment (No. 5). Princeton University Press. 1972.

112. Edmonds CA, Lillie AS, Cavalli-Sforza LL. Mutations arising in the wave front of an expanding population. Proc Natl Acad Sci U S A. 2004;101(4):975-9. 